\title{
Application and Evaluation of the China Meteorological Assimilation Driving Datasets for the SWAT Model (CMADS) in Poorly Gauged Regions in Western China
}

\author{
Xianyong Meng ${ }^{1,2, * \mathbb{C}}$, Xuesong Zhang ${ }^{3}$, Mingxiang Yang ${ }^{4}$, Hao Wang ${ }^{4}$, Ji Chen ${ }^{2, *}$, \\ Zhihua $\operatorname{Pan}^{1}$ and Yiping $W^{5}$ (D) \\ 1 College of Resources and Environmental Science, China Agricultural University (CAU), \\ Beijing 100094, China; panzhihua@cau.edu.cn \\ 2 Department of Civil Engineering, The University of Hong Kong (HKU), Pokfulam 999077, Hong Kong, China \\ 3 Joint Global Change Research Institute, Pacific Northwest National Laboratory and University of Maryland, \\ College Park, MD 20740, USA; xuesong.zhang@pnnl.gov \\ 4 State Key Laboratory of Simulation and Regulation of Water Cycle in River Basin, Beijing 100038, \\ China \& China Institute of Water Resources and Hydropower Research, Beijing 100038, China; \\ yangmx@iwhr.com (M.Y.); wanghao@iwhr.com (H.W.) \\ 5 Department of Earth and Environmental Science, School of Human Settlements and Civil Engineering, \\ Xi'an Jiaotong University, Xi'an 710049, China; yipingwu@xjtu.edu.cn \\ * Correspondence: xymeng@cau.edu.cn (X.M.); jichen@hku.hk (J.C.); Tel.: +86-10-6035-5970 (X.M.)
}

Received: 9 September 2019; Accepted: 13 October 2019; Published: 18 October 2019

check for

Abstract: The temporal and spatial differentiation of the underlying surface in East Asia is complex. Due to a lack of meteorological observation data, human cognition and understanding of the surface processes (runoff, snowmelt, soil moisture, water production, etc.) in the area have been greatly limited. With the Heihe River Basin, a poorly gauged region in the cold region of Western China, selected as the study area, three meteorological datasets are evaluated for their suitability to drive the Soil and Water Assessment Tool (SWAT): China Meteorological Assimilation Driving Datasets for the SWAT model (CMADS), Climate Forecast System Reanalysis (CFSR), and Traditional Weather Station (TWS). Resultingly, (1) the runoff output of CMADS + SWAT mode is generally better than that of the other two modes (CFSR + SWAT and TWS + SWAT) and the monthly and daily Nash-Sutcliffe efficiency ranges of the CMADS + SWAT mode are 0.75-0.95 and 0.58-0.77, respectively; (2) the CMADS + SWAT and TWS + SWAT results were fairly similar to the actual data (especially for precipitation and evaporation), with the results produced by CMADS + SWAT lower than those produced by TWS + SWAT; (3) the CMADS + SWAT mode has a greater ability to reproduce water balance than the other two modes. Overestimation of CFSR precipitation results in greater error impact on the uncertainty output of the model, whereas the performances of CMADS and TWS are more similar. This study addresses the gap in the study of surface processes by CMADS users in Western China and provides an important scientific basis for analyzing poorly gauged regions in East Asia.

Keywords: CMADS; SWAT; poorly gauged regions; comparative analysis

\section{Introduction}

Distributed hydrological models are widely used in the assessment of the impacts of climate change on surface process, hydrological processes, and water balance [1]. For these models to be able to provide reliable simulation products that can support water and land management practices, there is an 
increasing need for meteorological forcing data with high precision and spatiotemporal resolution [2,3]. Recent studies have shown that quality of meteorological data represents a major source of uncertainty in determining model performance [1-5]; improving data accuracy is therefore essential to effectively reduce model uncertainty [6,7]. A variety of atmospheric reanalysis datasets [8-15] have been widely used in hydrologic modeling studies [16-21]. Examples of such sets include: Climate Forecast System Reanalysis (CFSR) [10], produced by the National Centers for Environmental Prediction (NCEP) [8]; the (R1)-NCEP/National Center for Atmospheric Research (NCAR) reanalysis dataset, the (R2)-NCEPDepartment of Energy (DOE) reanalysis dataset [9-11]; European Centre for Medium-Range Weather Forecast (ECMWF) Reanalysis-Interim (ERA-Interim) [12], ECMWF Reanalysis-15 (ERA-15) [13], and ECMWF Reanalysis-40 (ERA-40) [14], produced by the European Centre for Medium-Range Weather Forecasts system (ECMWF); and Modern Era Retrospective-Analysis for Research and Applications (MERRA) [15] by the National Aeronautics and Space Administration (NASA). Additionally, output data from global or regional climate models and corresponding downscaled data are widely used to drive large-scale hydrological models [15-21]. Since the mid-1990s, the United States, European Union, Japan, and others have implemented a series of global atmospheric data reanalysis plans, which have yielded three rounds of reanalysis to date. The first generation of reanalysis produced the NCEP/NCAR global atmosphere reanalysis datasets, covering the period from 1948 onward [10], the ECMWF ERA-15 datasets covering 1979-1993 [16], and the NASA Data Assimilation Office ERA-15 datasets covering 1980-1995 [22,23]. The second generation of reanalysis datasets include the NCEP/DOE reanalysis (1979 onward) [11], ERA-40 (1958-2001) by ECMWF [14,24], and JRA-25 (1979 onward) by the Japan Meteorological Agency and the Central Research Institute of the Electric Power Industry [25]. The recently completed third generation of reanalysis datasets include ERA-Interim (1979 onward) by ECMWF [26], CFSR (1979 onward) by NCEP [10], MERRA (1979 onward) by NASA [15], and the Japanese 55-year ReAnalysis (JRA-55) (1958-2012) by the Japan Meteorological Agency (JMA) [27]. JRA-55 has two additional versions: JRA-55C (1972-2012, only fuses routine observations) and JRA-55AMIP (1958-2012, no observational fusing; equivalent to climate simulation). Recently, a number of datasets that include information beyond pure atmospheric reanalysis have been produced. For example, the 20th-century reanalysis (20CR,1871-2008) produced by the National Oceanic and Atmospheric Administration (NOAA)/Earth System Research Laboratory (ESRL) and the Cooperative Institute for Research in Environmental Sciences at the University of Colorado [28] adopted Ensemble Kalman Filter (EnKF) assimilation technology to fuse surface air pressure observations with aerosol reanalysis (MERRA-AERO, 2000-) [29] and atmospheric chemistry reanalysis (MACC, 2003-) [30] generated by NASA and ECMWF, respectively. Reanalysis can be used in long-term climate change research to produce long-term, continuous, and global four-dimensional (4D) datasets; such datasets allow an in-depth understanding of atmospheric circulation and its effects on climate formation, thereby facilitating the systematic study of the Earth's atmosphere. Recently, reanalysis data have been widely used for a variety of research purposes, including climate monitoring, seasonal forecasting, climate change modeling and diagnosis, global and regional water cycle and energy balance monitoring, and climate mode verification.

Although reanalysis datasets use different weather patterns and assimilation systems, all apply business-mature numerical forecasting models to produce patterns and assimilation systems. For example, NCEP-NCAR (NCEP1) uses the GSM (T62) business numerical model and the January 1995 Spectral Statistical Interpolation assimilation system; NCEP-DOE (NECP2) uses modified and improved versions of the model and assimilation systems used by NCEP1; ERA-40 uses the T159 integration forecasting system (IFS) produced by ECMWF with improved Three-Dimensional (3D) Variational Data Assimilation (3DVar) technology to assimilate data (ERA-40 ceased refreshing after August 2002); ERA-Interim uses the ECMWF IFS (T255) and a 4D Variational Data Assimilation (4DVAR) assimilation system, a continuous product of ERA-40. ERA-Interim both improves on the horizontal resolution of ERA-40 (T159 -> T255) and applies a more advanced 4DVar technology. JRA-25 uses a T106 global spectrum mode (JMA 2002) with a 3DVar-based assimilation system. NCEP has 
built a real-time updated CFSR global reanalysis dataset. CFSR takes a new approach in using a global high-resolution atmosphere-ocean-land-ice coupled system with a Global Forecast System (GFS) ocean mode, a Modular Ocean Model-Version 4 (MOM4), and a Noah land mode. The discrete CFSR assimilation system uses GIS-3DVAR, Global Ocean Data Assimilation System (GODAS), and Global Land Data Assimilation System (GLDAS) for atmosphere, ocean-ice, and land modes, respectively. NASA's MERRA global reanalysis dataset, which uses a Goddard Earth Observing System, Version 5 (GEOS-5) Atmospheric Data Assimilation System (ADAS) based on 3DVar Geographic Information System (GIS) technology with a horizontal resolution of $38 \mathrm{~km}$ (T382), obtains significantly improved water cycle simulation results. The JMA-55 reanalysis dataset adapts the December 2009 TL319L60 (approximately $60 \mathrm{~km}$ ) data to a 4DVar assimilation system (T106 inner model) and an offline Simple Biosphere Model (SiB) (using 3-h atmospheric forcing data).

Many useful findings have been obtained through the reliability analyses of reanalysis datasets of the types described above. However, each reanalysis dataset has its own advantages and disadvantages, and no specific approach results in a uniform performance across geographic regions and time periods. For example, Zhao et al. [31] found that ERA-40 has a higher confidence level than NCEP-2. Huang's [32] analysis of China sounding data revealed that, while ERA-40 produces better pre-1970s interdecadal East-Asia climate variation results, and NCEP/MCAR produces a better description of troposphere geopotential height and temperature in Inner Mongolia and North China than ERA-40 for 1970 and afterward. Although JRA-25 and the JMA Climate Data Assimilation System (JCDAS) produce the best 6-h global precipitation distributions and quantities over time and space, the low resolution of JRA-25 renders it unsuitable for mesoscale analysis [24]. Najafi et al. [16] used the CSFR dataset to drive the Sacramento Soil Moisture Accounting Model (SAC-SMA) and analyzed runoff in the Donghe River basin based on water supplied by snowfall and melt. Fuka et al. [17] used precipitation and temperature data from the CFSR dataset (http://cfs.ncep.noaa.gov/cfsr/) to drive a soil and water assessment tool (SWAT) model and found that SWAT simulations driven by CSFR outperformed those driven by TWS data. Smith et al. (2013) assessed the water balance relations between the land surface and atmosphere produced by ERA-Interim, CSFR, and MERRA and concluded that all of these datasets could skillfully reflect seasonal changes in water balance. Lavers et al. [19] used ERA-Interim, CFSR, NCEP-NCAR, and MERRA data to study the relation between winter flooding and large-scale climate activity and demonstrated that all of these datasets could reflect a consistent relationship between the two. Quadro et al. [20] found that CSFR outperformed NCEP Reanalysis II (NCEP-2) and MERRA in simulating South American water balance. Wei et al. [21] used CFSR and TRMM to simulate three cyclones passing through the Taiwan Strait. Despite its wide use, the CFSR dataset has been shown to produce large uncertainties in precipitation frequency and intensity, although it does successfully capture large-scale precipitation climatology [33,34]. Precipitation is one of the most important factors in the processes of generating runoff, but, because of a lack of reliable observations, the CFSR dataset has low usability and accuracy in modelling precipitation in China.

As noted in the IPCC fourth assessment report [35], global climate models (GCMs) are not completely applicable in modeling regional climate patterns, as a result of their coarse resolutions. Several studies have shown that GCMs cannot be directly applied in the assessment of future regional-scale hydrological changes [36]. Regional climate models have higher spatial-temporal resolutions than GCMs and have been applied successfully in finer-grained simulation. For example, $\mathrm{Lu}$ et al. [37] used the precipitation output of Mesoscale Community Compressible (MC2) to drive a land-atmosphere coupling model Xin'anjiang with enhanced forecasting precision and lead time, although Wang et al. [38] obtained somewhat worse results by using the Regional Climate Model-version 3 (RegCM3) regional climate model to drive a semi-distributed SWAT hydrological model. To validate the model for use in China, Jeremy et al. [39] used RegCM3 to simulate and analyze monthly and seasonal rules of precipitation in winter and summer in the monsoon region of East Asia and found that the model produces large precipitation simulation errors, particularly in winter. 
Compared to South-Eastern China, the western region of the country has a sparse distribution of meteorological stations, which acts as a significant constraint on large-scale modeling. Given the poor performance of regional climate models and reanalysis datasets in China, it is necessary to develop a high resolution dataset covering the entire country and evaluate its performance in large-scale hydrological modeling. To this end, this paper presents the newly developed China Meteorological Assimilation Driving Datasets for the SWAT model (CMADS), which can be used for large-scale, SWAT-based hydrological modeling. After comparing the modeling performance of CMADS results to those obtained using CFSR and TWS datasets, the added value of the CMADS dataset in the large-scale modeling of the Heihe River Basin (HRB) in China is assessed.

\section{Study Region}

The Heihe River basin (HRB) $\left(\mathrm{E} 98^{\circ} 34^{\prime}-101^{\circ} 09^{\prime} \mathrm{N} 37^{\circ} 43^{\prime}-39^{\circ} 06^{\prime}\right)$ contains the second largest inland river in China, which originates from Qilian Mountain in the south and flows out of the mountain at the Ying Luoxia hydrological station. The HRB has higher altitudes in the south and west than in the north and east and is characterized by scarce precipitation, adequate sunshine, and a large diurnal temperature range. The total catchment area is $9973 \mathrm{~km}^{2}$ with an average elevation ranging from 1980.629 to $4029.827 \mathrm{~m}$ (Figure 1).

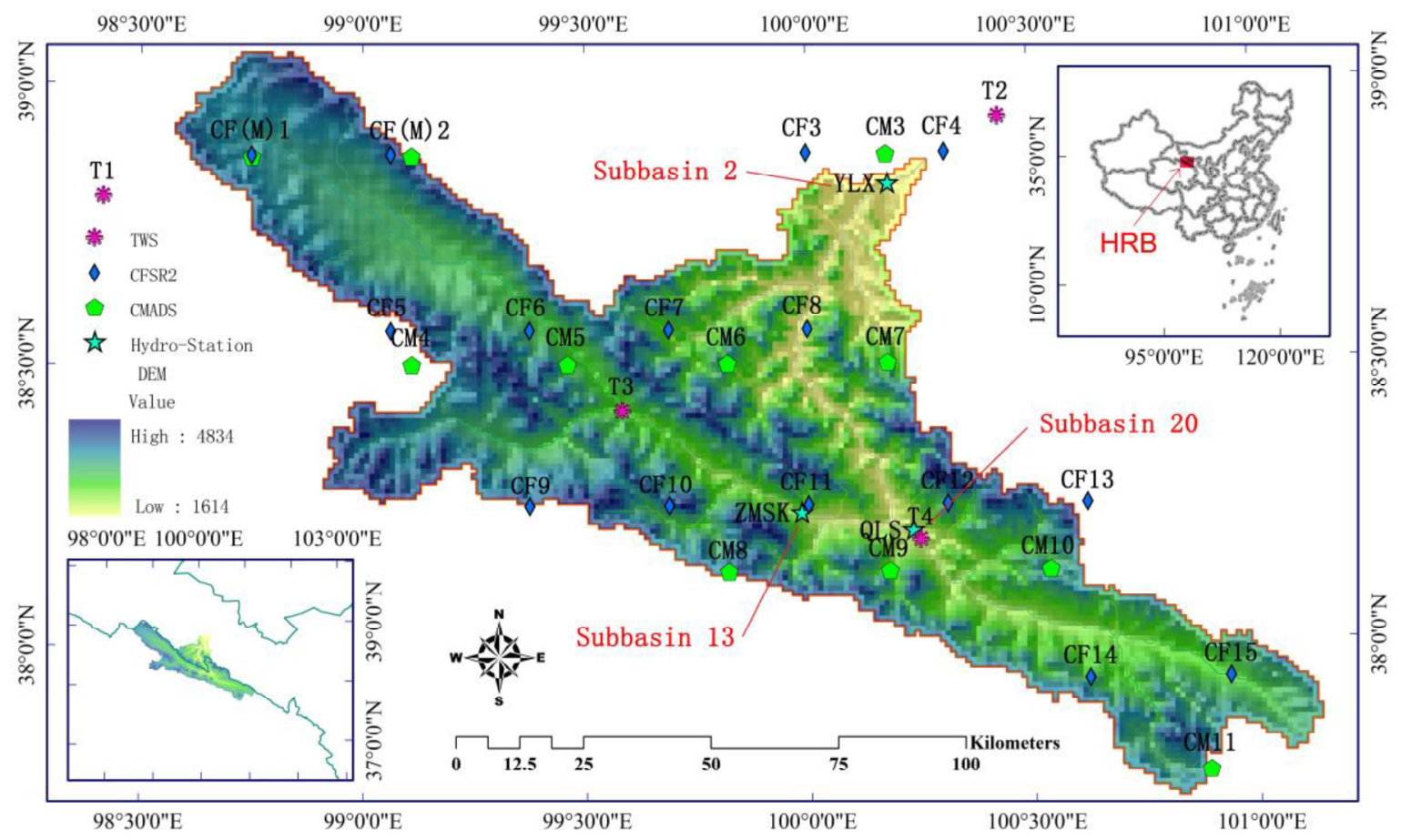

Figure 1. Distribution of meteorological stations and hydrological stations in the study area. YLX, ZMSK, and QLS are Ying Luoxia (Sub-basin 2), ZhaMashenke (Sub-basin 13), and Qilian Mountain (Sub-basin 20) stations, respectively.

The HRB has an average annual precipitation of 300-700 $\mathrm{mm}$ and average annual temperatures ranging between -3 and $7{ }^{\circ} \mathrm{C}$. The mountain region, located at altitudes above $4500 \mathrm{~m}$, is covered with ice and snow, with the altitude of the snow line increasing from east to west. Due to the large amount of precipitation and glaciations, as well as the underling mountainous surface and good vegetation distribution, the Qilian Mountain area serves as the upstream region of the entire HRB. Although the multi-annual average runoff at Ying Luoxia station is 1.58 billion $\mathrm{m}^{3}$, the annual change in the HRB runoff changes is low, with a typical ratio of maximum to minimum runoff smaller than three. There is, however, large intra-seasonal variability, with May and June accounting for $12-25 \%$ of the annual 
runoff, and July and September, 50-55\%. Financial revenue in the region primarily depends upon animal husbandry, and there are abundant water resources and developed irrigation facilities.

\section{Materials and Methods}

Here, the SWAT model is applied to the HRB as a study region to assess the added value of the CMADS dataset. Using streamflow observations from three hydrological stations in the region obtained from the HRB Authority, three simulations are conducted using SWAT models driven by CMADS, CFSR, and TWS data, respectively. Finally, the simulation results are compared with observations

\subsection{Land Surface Input Data}

\subsubsection{Digital Elevation Model}

The spatial input data of the SWAT model includes the Digital Elevation Model (DEM), the river network, and land use data. The DEM data were obtained from the Shuttle Radar Topography Mission (SRTM)- $(90 \mathrm{~m})$ dataset, which is archived by the Consultative Group on International Agricultural Research (CGIAR)-Consortium for Spatial Information (CSI) SRTM 90 database (http://srtm.csi.cgiar.org/SELECTION/inputCoord.asp) [40]. The DEM data were extracted and analyzed by the SWAT model in this study. The slope states of the watershed are min: 0.13 , max: 68, mean: 13.2, and median: 11.6.

\subsubsection{Soil Distribution and Land Use Data}

Soil properties (Figure 2a) and land use (Figure 2b) categories determine the characteristics of flow generation and concentration in the various Hydrological Response Units (HRUs) of the SWAT model. The soil data used in this study are obtained from the China Soil Dataset (v1.1), which is based on the World Soil Database [40]. Soil categories in the basin include: Eutric Leptosols (31.114\%), Gelic Leptosols (28.687\%), Luvic Kastanozems (8.673\%), Luvic Gypsisols (6.498\%), Rendzic Leptosols (4.342\%), Gelic Gleysols (3.339\%), Mollic Leptosols (2.517\%), Luvic Chernozems (2.447\%), Haplic Kastanozems (2.316\%), Cumulic Anthrosols (2.206\%), Gelic Cambisols (1.564\%), Calcic Gleysols (1.374\%), Haplic Chernozems (1.344\%), Terric Histosols (0.772\%), Calcaric Phaeozems (0.702\%), Calcaric Fluvisols $(0.622 \%)$, Calcic Kastanozems (0.602\%), Haplic Greyzems (0.340\%), Mollic Gleysols $(0.311 \%)$, Glaciers $(0.120 \%)$, and Haplic Gypsisols $(0.110 \%)$; the percentage figures indicate the ratio of the area of the soil category to that of the entire watershed area. Eutric Leptosols $(31.114 \%)$ and Gelic Leptosols $(28.687 \%)$ are the dominant soil types in the basin. In the HWSD database, the ratio of GRAVEL, SAND, SILT, and CLAY of the two dominant soils are $45 \%$ Vol., (77\% wt.), $11 \%$ wt. (12\% wt.), $24 \%$ wt. ( $46 \%$ wt.), $34 \% \mathrm{wt}$. (20\% wt.), respectively. The database shows that DRAINAGE of these two types of soils are Moderate and Imperfect, respectively. This indicates that the drainage effect of Eutric Leptosols, which is the most widely distributed soil, is moderate, but better than that of Gelic Leptosols.

The land use map (Global Land Cover Database for the year 2000, GLC2000) is obtained from the China West Data Centre (WestDC) [41]. The main land category in the research area is meadow, accounting for $64.173 \%$ of the watershed area, followed by meadow bromegrass $(24.747 \%)$, bare rocks $(7.079 \%)$, ice $(1.253 \%)$, desert grassland $(0.963 \%)$, farmland $(0.602 \%)$, needle-leaved deciduous forest $(0.461 \%)$, gravels $(0.421 \%)$, bush $(0.221 \%)$, desert $(0.07 \%)$, and plain grassland $(0.01 \%)$. The land use data are matched with corresponding similar codes in the SWAT land use database and expressed as the following land use types: MEDW, BROM, ROCK, ICE, DEGA, AGRL, FRSD, GRAV, RNGB, DESE, and PAST, respectively. To guarantee the accuracy of the ice data, the land use data were overlaid onto the Second Glacier Inventory Dataset of China [42,43].

To ensure model consistency, the spatial resolution of the DEM, soil and land use data were all set to $1 \mathrm{~km}$ and the projection coordinates were set using Beijing_1954_GK_Zone_17N. 

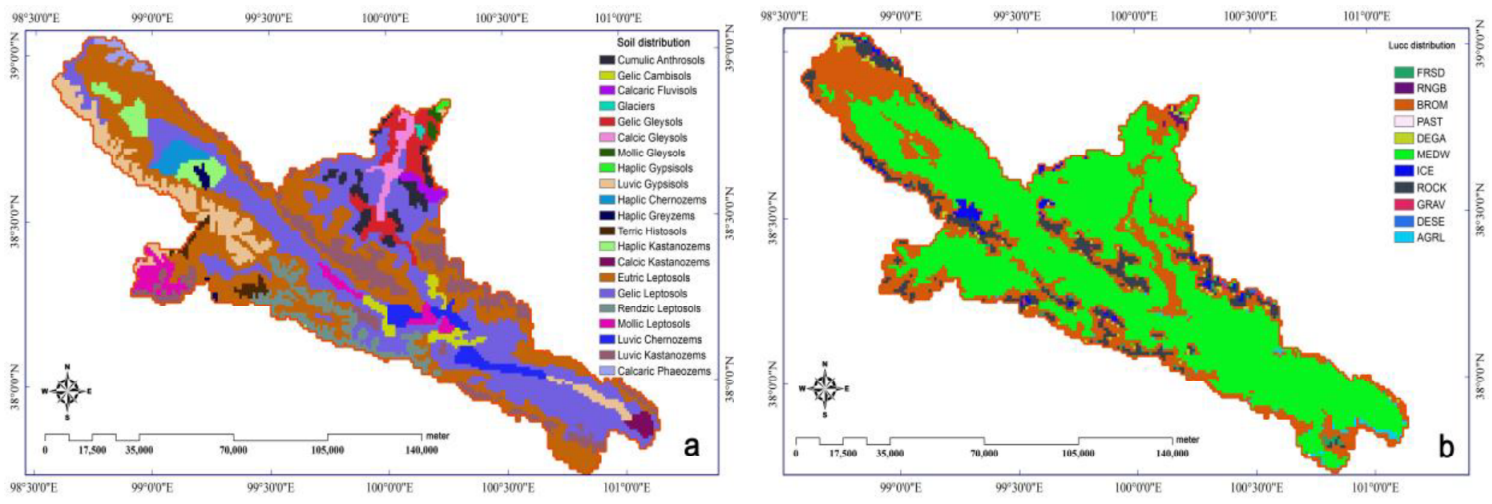

Figure 2. Soil (a) and Lucc (b) distribution of Heihe River basin (HRB).

\subsection{Hydrological Verification Data}

Daily streamflow observations are taken at the ZhaMashenke, Qilian Mountain, and Ying Luoxia hydrological stations. The details of each station are listed in Table 1.

Table 1. Hydrological stations data statistics in Heihe River Basin (HRB).

\begin{tabular}{cccccc}
\hline Station Name & $\begin{array}{c}\text { Nature } \\
\text { Sub-Basin Area } \\
\left(\mathbf{k m}^{\mathbf{2}} \mathbf{)}\right.\end{array}$ & Latitude $\left(^{\circ}\right)$ & Longitude $\left.\mathbf{(}^{\circ}\right)$ & $\begin{array}{c}\text { Station } \\
\text { Elevation }(\mathbf{m})\end{array}$ & $\begin{array}{c}\text { Data Period } \\
\text { (year) }\end{array}$ \\
\hline Ying Luoxia & 243 & 38.82 & 100.18 & 1700.4 & $2009-2013$ \\
Qilian Mountain & 310 & 38.20 & 100.23 & 3020.1 & $2009-2013$ \\
ZhaMashenke & 126 & 38.23 & 99.98 & 2810.2 & $2009-2013$ \\
\hline
\end{tabular}

\subsection{Atmospheric Forcing Input Data}

Three types of datasets were used to produce atmospheric data to force the SWAT model (Table 2). The HRB has four national basic meteorological observation stations: Tuo Le (T1), Ye Niugou (T3), Qilian (T4), and Zhang Ye (T2); which can be considered to produce the most authoritative spatial results. To assess the accuracy of CFSR and CMADS in modeling the basin, their respective interpolation results were analyzed at TWS locations T1-T4. The TWS data were used to obtain daily average air pressure, average wind speed, average temperature, average relative humidity, daily maximum/minimum temperatures, and daily precipitation and sunshine duration, with missing observational values filled by the SWAT model's embedded weather generator. The SWAT models use the observations to calculate multi-annual climate conditions [6] and then apply the centroid method to interpolate station elements [44].

\subsubsection{TWS}

The TWS dataset represents data from traditional weather stations; Daily Datasets of Surface Climate Data in China (V3.0) are obtained from National Meteorological Information Center (https://data.cma.cn/). These datasets contain data from 699 basic meteorological stations in China, and include the daily data of air pressure, temperature, precipitation, evaporation, relative humidity, wind speed, and sunshine hours since January 1951. Here, four traditional weather stations are selected in the Heihe River Basin: Tuo Le (T1), Ye Niugou (T3), Qilian (T4) and Zhang Ye (T2) (Figure 1).

\subsubsection{CFSR}

The CFSR dataset, which is produced by the American National Environmental Forecasting Center [8], is a high-resolution global reanalysis dataset covering $98^{\circ} 34^{\prime}-101^{\circ} 09^{\prime} \mathrm{E}$ and $37^{\circ} 43^{\prime}-39^{\circ} 06^{\prime} \mathrm{N}$ with a T382 atmospheric resolution, corresponding to $38 \mathrm{~km}$ horizontally and 64 floors vertically. 
We interpolate CFSR data at intervals of $0.313^{\circ}$ using bilinear interpolation technique and obtain 15 interpolating points (CF1-CF15) in the study region. The spatial resolution is $0.313^{\circ} \times 0.313^{\circ}$ and the temporal resolution is daily from January 1, 2008 to December 31, 2013, with data including precipitation, maximum/minimum temperatures, wind speed, relative humidity, and solar radiation. Although the SWAT model website also recommends using the CFSR dataset to drive and build models globally, the effectiveness of driving the SWAT model using the CFSR dataset in China has not been systematically verified.

Table 2. Three types of atmospheric forcing data: Traditional Weather Station (TWS), Climate Forecast System Reanalysis (CFSR), and China Meteorological Assimilation Driving Datasets for the SWAT model (CMADS).

\begin{tabular}{|c|c|c|c|}
\hline Dataset & TWS & CFSR & CMADS \\
\hline Elements & $\begin{array}{c}\text { Daily average air pressure, } \\
\text { daily average wind speed, } \\
\text { daily average temperature, } \\
\text { daily average relative } \\
\text { humidity, daily maximum/ } \\
\text { minimum temperatures, } 24 \mathrm{~h} \\
\text { precipitation, and sunshine } \\
\text { duration }\end{array}$ & $\begin{array}{c}\text { Daily accumulative } \\
\text { precipitation, daily } \\
\text { maximum/minimum } \\
\text { temperatures, daily } \\
\text { average wind speed, daily } \\
\text { average relative humidity, } \\
\text { and daily accumulative } \\
\text { solar radiation }\end{array}$ & $\begin{array}{c}\text { Daily maximum/minimum } \\
\text { temperatures, daily } \\
\text { average wind speed, daily } \\
\text { average relative humidity, } \\
\text { daily accumulative } \\
\text { precipitation, and daily } \\
\text { accumulative solar } \\
\text { radiation }\end{array}$ \\
\hline $\begin{array}{l}\text { Data original spatial } \\
\text { range }\end{array}$ & $\begin{array}{c}4.00^{\circ} \mathrm{N} \sim 53.31^{\circ} \\
\mathrm{N} 73.40^{\circ} \mathrm{E} \sim 135.05^{\circ} \mathrm{E}\end{array}$ & Global & $0^{\circ} \mathrm{N} \sim 65^{\circ} \mathrm{N}, 60^{\circ} \mathrm{E} \sim 160^{\circ} \mathrm{E}$ \\
\hline $\begin{array}{c}\text { Data spatial range of } \\
\text { this study }\end{array}$ & $37^{\circ} \mathrm{N} \sim 39^{\circ} \mathrm{N}, 98^{\circ} \mathrm{E} \sim 101^{\circ} \mathrm{E}$ & $\begin{array}{c}24.5 .00^{\circ} \mathrm{N} \sim 57.00^{\circ} \mathrm{N} \\
44.00^{\circ} \mathrm{E} \sim 129.00^{\circ} \mathrm{E}\end{array}$ & $\begin{array}{l}37.5^{\circ} \mathrm{N} \sim 39.17^{\circ} \mathrm{N} \\
98.5^{\circ} \mathrm{E} \sim 101.17^{\circ} \mathrm{E}\end{array}$ \\
\hline Data timescale & 2008.1.1-2013.12.31 & 2008.1.1-2013.12.31 & 2008.1.1-2013.12.31 \\
\hline $\begin{array}{l}\text { Data original } \\
\text { resolution ratio }\end{array}$ & / & $0.313^{\circ}, 0.5^{\circ}, 1.0^{\circ}, 1.9^{\circ}, 2.5^{\circ}$ & $\begin{array}{c}0.333^{\circ}, 0.25^{\circ}, 0.125^{\circ}, \\
0.0625^{\circ}\end{array}$ \\
\hline $\begin{array}{l}\text { resolution ratio of } \\
\text { this study }\end{array}$ & / & $0.313^{\circ}$ & $0.333^{\circ}$ \\
\hline $\begin{array}{c}\text { No. of stations } \\
\text { imported by SWAT } \\
\text { model }\end{array}$ & $4(\mathrm{~T} 1-\mathrm{T} 4)$ & 15 (CF1-CF15) & 11 (CM1-CM11) \\
\hline
\end{tabular}

\subsubsection{CMADS}

The CMADS (obtainable online at http://www.cmads.org) is a public-domain dataset developed by Dr. Xianyong Meng at the China Agriculture University [45-48]. CMADS' integration of air temperature, air pressure, humidity, and wind velocity data is primarily achieved through the Local Analysis and Prediction System (LAPS)/Space Time Multiscale Analysis System (STMAS) system [45]. Precipitation data are stitched using the Climate Prediction Center Morphing (CMORPH)-produced global precipitation products and data from the China National Meteorological Information Centre [47], which contain daily precipitation records observed at 2400 national meteorological stations, in addition to the CMORPH satellite inversion precipitation products. An inversion algorithm for incoming solar radiation at the ground surface uses the discrete longitudinal method [47] to calculate radiation transmission. The resolutions of CMADS V1.0, V1.1, V1.2, and V1.3 are $1 / 3^{\circ}, 1 / 4^{\circ}, 1 / 8^{\circ}$, and $1 / 16^{\circ}$, respectively.

The CMADS model was completed over a 11-year period from 2008 to 2018 and has been applied to many watersheds in East Asia [49-66], achieving good simulations.

\subsubsection{Evaluation of CFSR and CMADS Based on TWS}

The SWAT model used in this study required the interpolation of 11 stations (CM1-CM11) from the CMADS V1.0 model (resolution ratio: $1 / 3^{\circ}$ ). The CMADS-derived distributions of multi-annual total precipitation and maximum/minimum temperatures in the Ying Luoxia River Basin are shown in 
Figure 3. This study emphasizes verifying the utility of the CMADS dataset for driving hydrological model in China.
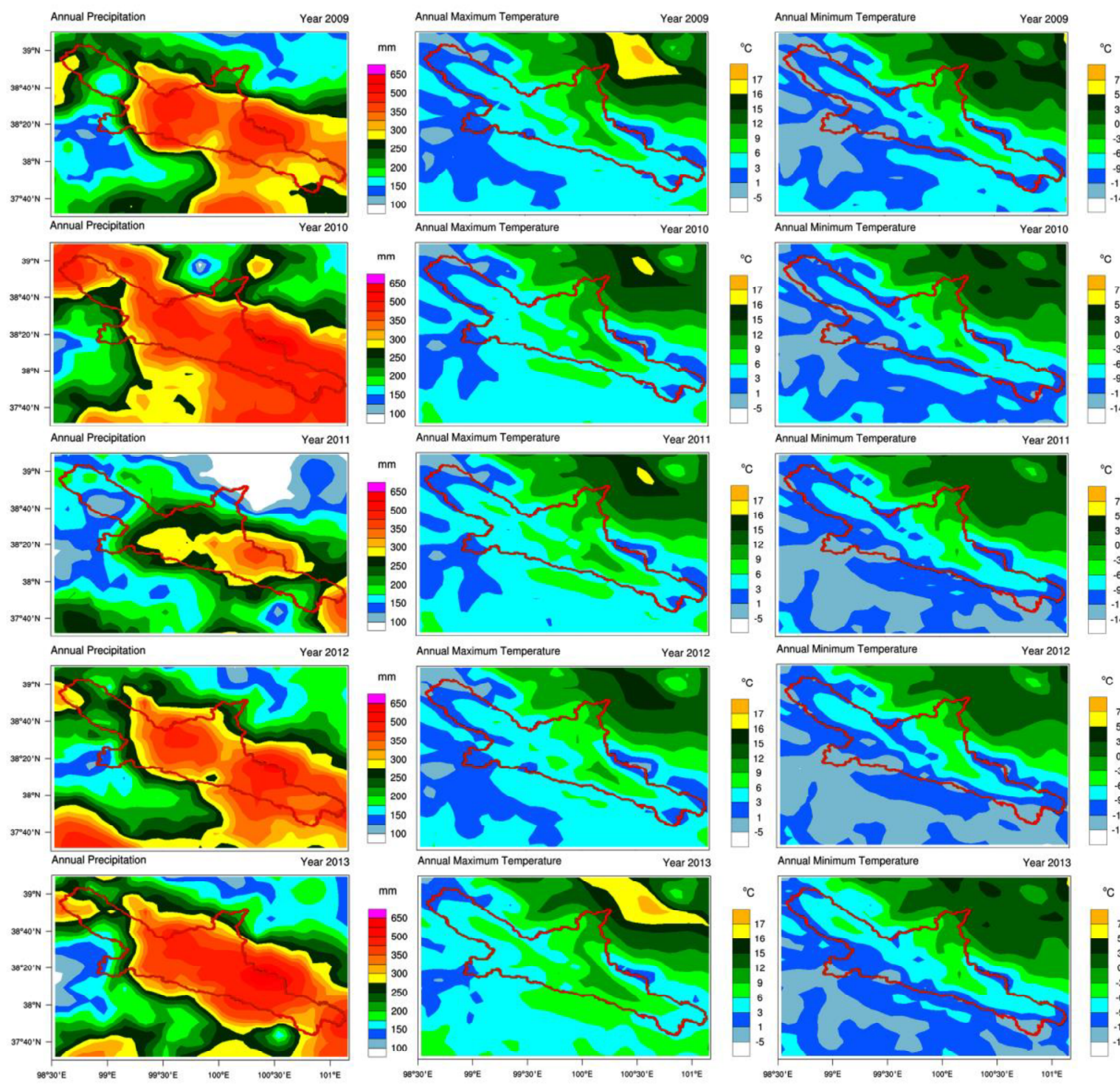

Figure 3. Distribution of CMADS elements (such as annual precipitation, the highest and lowest temperature distribution) in the Heihe River Basin (HRB) (red area) from 2009 to 2013.

Our preparatory research revealed that there are few meteorological stations in Western China, making large-scale hydrological simulation difficult without interpolation. Accordingly, CMADS and CFSR had obvious advantages over TWS data, and 11 and 15 meteorological stations were extrapolated by CMADS and CFSR, respectively, from the four TWSs (T1-T4) in the basin. Additionally, we found missing data values at each station, with missing ratios of up to $3.395 \%, 8.762 \%, 4.654 \%$, and $7.448 \%$ at TuoLe (T1), Zhang Ye (T2), Ye Niugou (T3), and Qilian (T4), respectively. This contrasts with the lack of missing values in the SWAT model-driven CMADS and CFSR datasets.

To quantitatively analyze the differences between the interpolated dataset results produced by CFSR and CMADS for the HRB, we extracted the spatial coordinates of the four TWSs in the study area (Figures 4 and 5) and evaluated the accuracy produced by the interpolated datasets relative to the observed data. The TWSs were located at the following spatial coordinates: $38.82,98.42$ (T1); 39.09, 100.29 (T2); 38.42, 99.59 (T3); and 38.18, 100.25 (T4). From this analysis, it was found that the goodness of fit between CMADS and TWS was better than that between CFSR and TWS, and that 
CMADS underestimated precipitation at all four stations from May-September between 2009 and 2011 (Figure 4). The maximum error in precipitation was $0.28 \mathrm{~mm}$ and the correlation coefficient was higher than 0.992, indicating a high fit between the CMADS and TWS datasets. The performance of CFSR was generally worse than that of CMADS, overestimating precipitation at each interpolation point over the period from 2009 to 2013 with errors of up to $1.15 \mathrm{~mm} / \mathrm{month}$. Additionally, maximum temperatures were underestimated at all four stations, with errors ranging from -5.93 to $-9.41{ }^{\circ} \mathrm{C} / \mathrm{month}$ (Figure 5 , T4). The evaluation results are listed in Table 3.
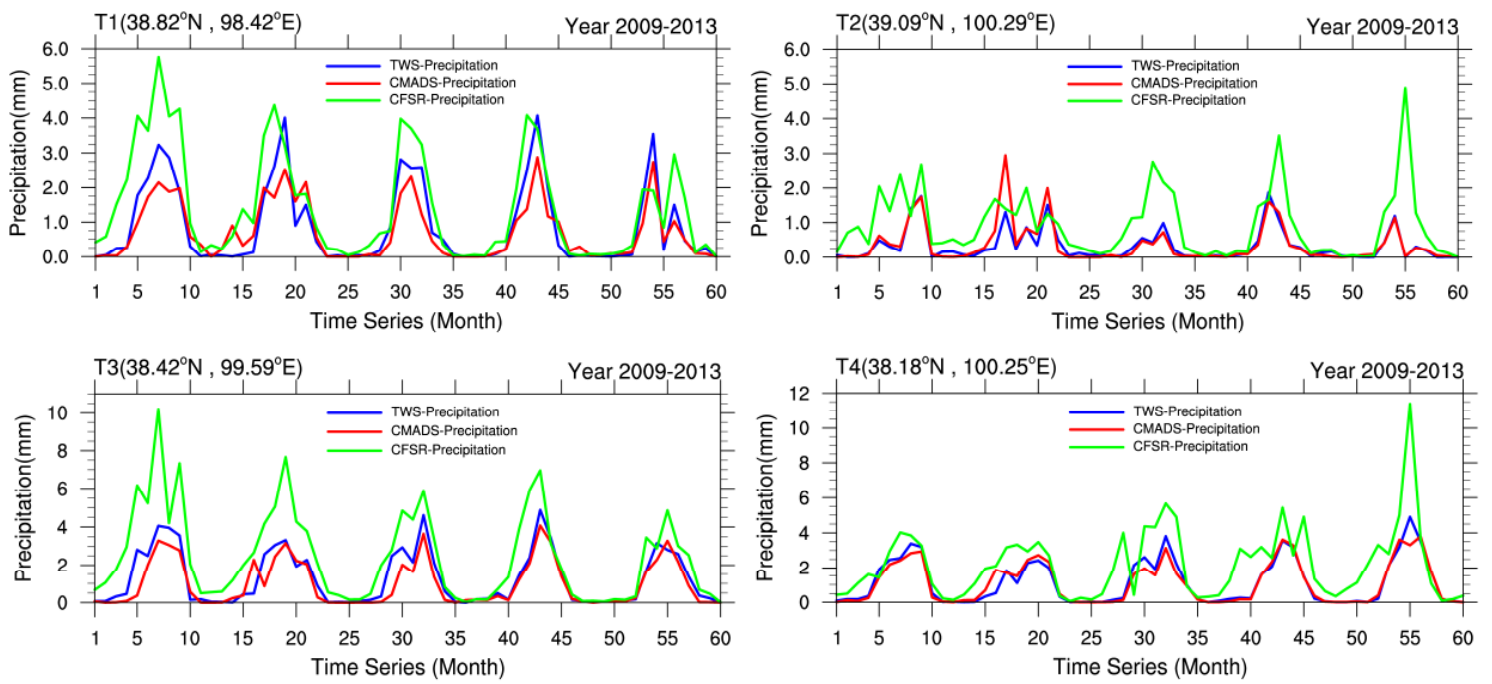

Figure 4. Average monthly precipitation according to TWS (blue), CMADS (red), and CFSR (green) at four sites (T1-T4) from 2009 to 2013.
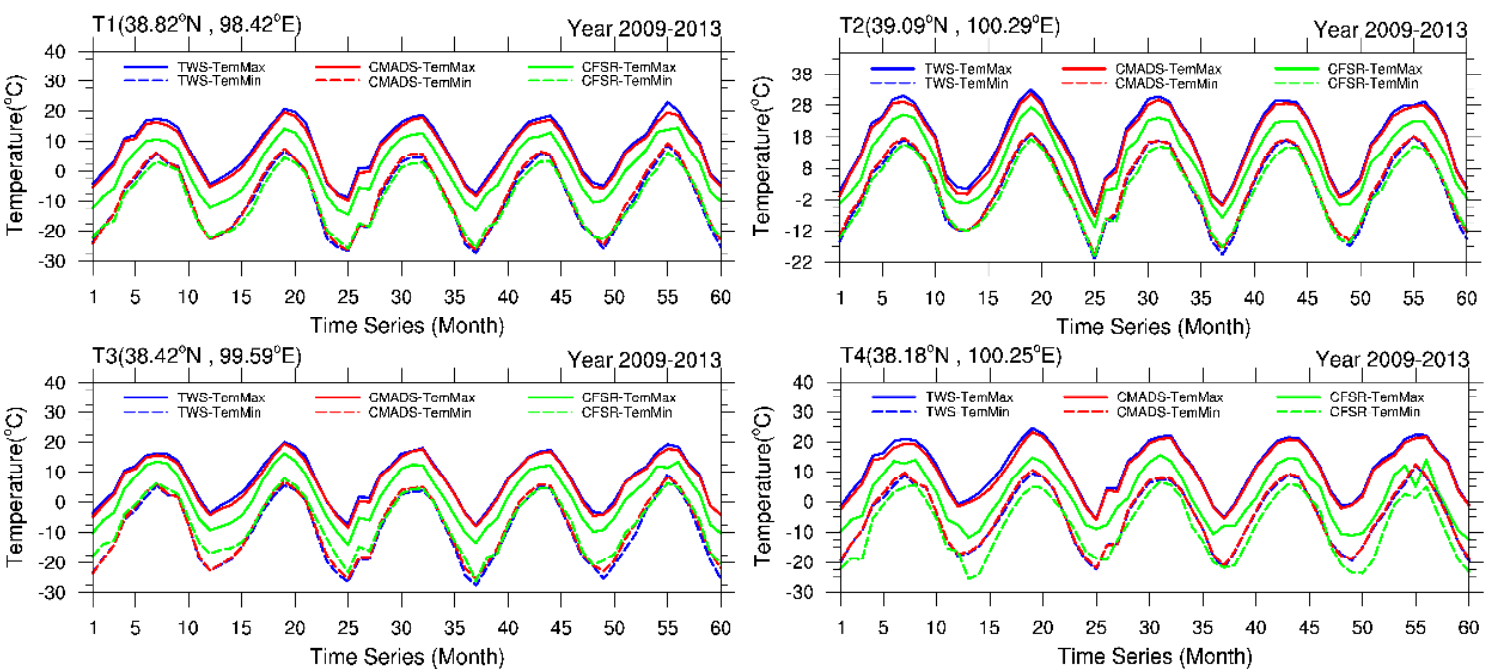

Figure 5. Maximum and minimum temperatures according to TWS (blue), CMADS (red), and CFSR (green) at four sites (T1-T4) from 2009-2013.

To further investigate the hydrological performance of the three datasets, they were each used to drive the SWAT model. 
Table 3. Correlation analysis for CFSR and CMADS based on TWS at four sites (T1-T4).

\begin{tabular}{ccccccccccccc}
\hline \multirow{2}{*}{ Dataset Elements } & \multicolumn{3}{c}{ TWS (T1) } & \multicolumn{3}{c}{ TWS (T2) } & \multicolumn{3}{c}{ TWS (T3) } & \multicolumn{3}{c}{ TWS (T4) } \\
\cline { 2 - 12 } & R2 & CORR & BIAS & R2 & CORR & BIAS & R2 & CORR & BIAS & R2 & CORR & BIAS \\
\hline CF-precipitation & 0.76 & 0.87 & 0.56 & 0.26 & 0.51 & 0.60 & 0.70 & 0.84 & 1.15 & 0.62 & 0.79 & 1.02 \\
CM-precipitation & 0.85 & 0.92 & -0.16 & 0.81 & 0.90 & 0.02 & 0.83 & 0.91 & -0.2 & 0.92 & 0.96 & -0.04 \\
CF-maximum temperature & 0.98 & 0.99 & -6.64 & 0.98 & 0.99 & -5.9 & 0.98 & 0.99 & -5.7 & 0.89 & 0.94 & -9.41 \\
CM-maximum temperature & 0.99 & 0.99 & -1.10 & 0.99 & 0.99 & -1.1 & 0.99 & 0.99 & -0.7 & 0.99 & 0.99 & -0.99 \\
CF-minimum temperature & 0.98 & 0.99 & -0.56 & 0.98 & 0.99 & -0.7 & 0.97 & 0.98 & 2.2 & 0.90 & 0.95 & -3.42 \\
CM-minimum temperature & 0.99 & 0.99 & 0.73 & 0.99 & 0.99 & 0.82 & 0.99 & 0.99 & 1.1 & 0.99 & 0.99 & 0.40 \\
\hline
\end{tabular}

CF and CM represent CFSR and CMADS, respectively; $\mathrm{R}^{2}$, CORR, and BIAS are the deterministic coefficient, correlation coefficient, and bias, respectively. Negative bias represents a value underestimated by TWS observations, and positive bias a value over-estimated by observations.

\subsubsection{SWAT Model}

The SWAT model is a semi-distributed model that can simulate basin-scale hydrology, sediment dynamics, and non-point source pollution [6]. Unlike other grid-based distributed hydrological models, the SWAT model separates an individual basin into several independent HRUs with common land use characteristics, soil categories, and gradients. Since its initial publication, the model has been widely used around the world [7].

\section{Model Setting}

After dividing the study area into 24 sub-basins (among them, Qilian Mountains, Zha Mashenke, and Ying Luoxia, which are located in Sub-basin 20, Sub-basin 13, and Sub-basin 2, respectively) based on DEM information, the SWAT model was used to divide each sub-basin into several HRUs. The multiple HRUs were chosen to ensure that the details of land use, soil, and slope were retained, with the threshold set to 0 . In the SWAT model, the water balance of each HRU was calculated based on surface runoff, interflow, base flow, infiltration, river transfer loss, and evapotranspiration. Here, we refer to the three combinations of forcing data, i.e., CMADS, CFSR, and TWS with the SWAT model, as the CMADS + SWAT, CFSR + SWAT, and TWS + SWAT modes, respectively.

In all three of the modes, the Penman-Monteith method was applied to calculate potential evapotranspiration based on solar radiation, temperature, relative humidity, and wind speed. As there are no solar radiation data in the TWS dataset, the solar radiation under the TWS + SWAT mode was synthesized using the SWAT model's Markovian weather generator. Each mode applies methodology developed by the former US Soil Conservation Service (SCS) to input daily data to calculate surface runoff and develop an SCS curve, which is a non-linear relation between precipitation and initial loss. The surface runoff calculated for each HRU was then routed into the main channel and a river storage method based on a continuity equation is used to calculate main channel water flow.

By applying the centroid interpolation principle, the SWAT model can interpolate spatially discrete meteorological data at a single point within an overall basin [36]. To reduce errors caused by spatial dispersion and interpolation (particularly in mountainous areas) and increase the precipitation accuracy within the HRUs and natural sub-basins, information extracted from the HRB elevation dataset were extracted and used to identify several common-elevation areas. The elevation module of SWAT model was activated in this step. The model adjusts the spatial meteorological elements, such as precipitation, according to the extracted DEM information. The precipitation gradient is then used to simulate the precipitation distributions within the respective elevation areas based on precipitation generated through model output.

A simulation period of 2008-2013 was selected, with the year 2008 used for model spin-up and calibration, and verification periods from 2009-2010 and 2011-2013, respectively.

\section{Sensitivity Analysis}

The SWAT-CUP software developed by EWAGE [67] was used to analyze and calibrate the parameters of each mode. The Sequential Uncertainty Fitting (SUFI-2) algorithm [68,69] was used 
to run SWAT-CUP [70] in conducting model calibration, validation, and sensitivity and uncertainty analysis. This algorithm has many uncertainties for example, in terms of parameters, conceptual models, and input, but can attain a 95\% Prediction Uncertainty (95PPU) for most measured data. The 95PPU value was calculated at the $2.5 \%$ and $97.5 \%$ levels of the cumulative distribution of an output variable obtained through Latin hyper cube sampling. Sensitivity analysis was then used to analyze which runoff parameters (26 parameters in total) are most sensitive, from which a parameter sensitivity ranking driven by three types of meteorological data was derived.

\section{Model Calibration}

Parameter calibration is an important process in SWAT model building [71-73]. The 14 most sensitive parameters based on the simulated conditions [74] between 2009 and 2010 were chosen for calibration and used to validate the model performance from 2011 to 2013 for each dataset; on the basis of SWAT-CUP sensitivity analysis, the five most sensitive parameters were automatically calibrated in this study, and the remaining parameters were manually fine-tuned without much change in the model results. In this process, performance of the parameters was stably calibrated, followed by an attempted change to the range of other parameters to ensure that the problem of equifinality was solved. Following calibration at the monthly scale, the parameters were calibrated using daily data and validated against daily runoff. In this process, we considered the ratio between annual evaporation and runoff to ensure a reasonable level of simulated total evaporation, precipitation and runoff. The Qilian Mountain hydrological station was calibrated first, followed by the ZhaMashenke, and finally the Ying Luoxia station because the latter most station is downstream of the others and accurate calibration of upstream parameters can be a good foundation for downstream calibration.

Differences were found among the best parameters of the respective models. Table 4 lists the final values of the model parameters.

Table 4. Final value of Soil and Water Assessment Tool (SWAT) model parameters.

\begin{tabular}{|c|c|c|c|c|}
\hline Variable Name & Parameter Definition & TWS + SWAT & CFSR + SWAT & CMADS + SWAT \\
\hline ALPHA_BF.gw & Baseflow $\alpha$ factor & 0.337546 & 0.182795 & 0.437614 \\
\hline GW_DELAY.gw & $\begin{array}{l}\text { Delay time (day) of aquifer } \\
\text { replenishment }\end{array}$ & 307.377808 & 476.718750 & 295.687683 \\
\hline GWQMN.gw & $\begin{array}{l}\text { Water level threshold (mm) of shallow } \\
\text { aquifer when groundwater flowing } \\
\text { into the main river channel }\end{array}$ & 0.612660 & 0.411690 & -0.116476 \\
\hline GW_REVAP.gw & $\begin{array}{c}\text { Evaporation coefficient of } \\
\text { groundwater }\end{array}$ & 0.096742 & -0.005901 & 0.146628 \\
\hline SFTMP & $\begin{array}{c}\text { Average temperature }\left({ }^{\circ} \mathrm{C}\right) \text { at snowing } \\
\text { days }\end{array}$ & 6.248940 & -1.810063 & 5.092002 \\
\hline PLAPS & $\begin{array}{l}\text { Lapse rate of precipitation } \\
\qquad /\left(\mathrm{mm} \cdot \mathrm{km}^{-1}\right)\end{array}$ & 136.724258 & 178.032104 & 136.339050 \\
\hline SMFMN & $\begin{array}{l}\text { Snowmelt factor at } 21 \text { December } \\
\qquad / \mathrm{mm} \cdot\left(\text { day- }{ }^{\circ} \mathrm{C}\right)^{-1}\end{array}$ & 8.911116 & 7.507036 & 9.612769 \\
\hline SMFMX & Snowmelt factor at 21 June & 0.164362 & 5.421363 & 0.109247 \\
\hline TLAPS & Lapse rate of temperature $/\left({ }^{\circ} \mathrm{C} \cdot \mathrm{km}^{-1}\right)$ & -4.730556 & -8.429128 & -6.115168 \\
\hline
\end{tabular}


Model Assessment

The study used two evaluation indices: the Nash-Sutcliffe Efficiency (NSE) and determination efficiency (R2) [75]; both of these are widely used to assess model performance. NSE, a normal statistical formula that reflects the degree of fit between observed data and simulated results [76], is given by

$$
N S E=1-\frac{\sum_{i}\left(Q_{m}-Q_{s}\right)_{i}^{2}}{\sum_{i}\left(Q_{m, i}-\overline{Q_{m}}\right)^{2}},
$$

where $Q$ is the runoff variable, with $Q_{m}$ and $Q_{s}$ representing observed and simulated runoffs, respectively; $\overline{Q_{m}}$ represents the average observed runoff value. The NSE equation produced values ranging from $-\infty$ to 1 ; an NSE of one corresponds to a close fit between observed and simulated data, whereas NSEs between 0.1 and 1 correspond to acceptable simulation results, and NSEs less than zero correspond to poor results.

Determination efficiency reflects the degree of correlation between measured variables and is calculated as follows:

$$
\mathrm{R}^{2}=\frac{\left[\sum_{i}\left(Q_{m, i}-\overline{Q_{m}}\right)\left(Q_{s, i}-\overline{Q_{s}}\right)\right]^{2}}{\sum_{i}\left(Q_{m, i}-\bar{Q}_{m}\right)^{2} \sum_{i}\left(Q_{s, i}-\overline{Q_{s}}\right)^{2}}
$$

where $Q_{m}$ and $Q_{s}$ represent observed and simulated runoff values, respectively, and $i$ is the $i^{\text {th }}$ simulated or observed value.

Whereas some studies have chosen $\mathrm{R}^{2}>0.5$ and NSE $>0.5$ as criteria for a satisfactory SWAT model [77], others set NSE $>0.4$ as satisfactory [78]. This study adopted the evaluation criterion of Moriasi et al. [79], under which a monthly-scale simulation NSE $\geq 0.65$ or a daily-scale simulation NSE $\geq 0.5$ during the calibration period is considered acceptable [77].

\section{Results and Discussion}

\subsection{Daily-and Monthly-Scale Runoff Simulation Results by the Three Modes for Three Sub-Basins}

As discussed in the preceding section, three different modes (CMADS + SWAT, CFSR + SWAT, and TWS + SWAT) were used to obtain monthly and daily runoff series at three stations (Qilian Mountains, ZhaMashenke, and Ying Luoxia). Based on the model evaluation index developed by Santhi [77] and Moriasi [79], the CMADS + SWAT and TWS + SWAT modes both achieved satisfactory performance at the monthly-scale at all three stations (Table 5). At the ZhaMashenke station, on a monthly scale (Figures 6-8), the CMADS + SWAT results (Figure 7A) are better than those produced by TWS + SWAT (Figure 7B). As this location lacked a meteorological station, the CMADS dataset outperformed the TWS dataset. Nevertheless, the monthly simulation results for Sub-basin 2 (Ying Luoxia) produced by CMADS + SWAT were slightly over-estimated relative to those produced by TWS + SWAT, possibly because there was more precipitation under the CMADS + SWAT mode (May-Oct each year). Such over-estimation can also arise from the application of the centroid interpolation method and can be increased by secondary adjustment of the SWAT model and meteorological data. Regardless, the slightly over-estimated precipitation produced by CMADS for Ying Luoxia did not result in enhanced model simulation error (Table 5). 
Table 5. Evaluation of monthly and daily matching results at three stations driven by three different modes.

\begin{tabular}{|c|c|c|c|c|c|c|c|}
\hline & \multirow[t]{2}{*}{$\begin{array}{l}\text { Driving } \\
\text { Data }\end{array}$} & \multicolumn{2}{|c|}{$\begin{array}{c}\text { (Sub-Basin 20) Qilian } \\
\text { Mountain Control } \\
\text { Station }\end{array}$} & \multicolumn{2}{|c|}{$\begin{array}{c}\text { (Sub-Basin 13) } \\
\text { ZhaMashenke Control } \\
\text { Station }\end{array}$} & \multicolumn{2}{|c|}{$\begin{array}{l}\text { (Sub-Basin 2) Ying } \\
\text { Luoxia Control Station }\end{array}$} \\
\hline & & $N S$ & $R^{2}$ & NS & $R^{2}$ & NS & $R^{2}$ \\
\hline \multirow{3}{*}{ Monthly } & $\begin{array}{l}\text { CFSR + } \\
\text { SWAT }\end{array}$ & 0.32 & 0.21 & 0.49 & 0.50 & 0.45 & 0.46 \\
\hline & $\begin{array}{l}\text { CMADS + } \\
\text { SWAT }\end{array}$ & 0.75 & 0.85 & 0.95 & 0.95 & 0.92 & 0.95 \\
\hline & $\begin{array}{l}\text { TWS + } \\
\text { SWAT }\end{array}$ & 0.80 & 0.87 & 0.92 & 0.94 & 0.96 & 0.97 \\
\hline \multirow{3}{*}{ Daily } & $\begin{array}{l}\text { CFSR + } \\
\text { SWAT }\end{array}$ & 0.26 & 0.27 & 0.35 & 0.38 & 0.45 & 0.49 \\
\hline & $\begin{array}{c}\text { CMADS + } \\
\text { SWAT }\end{array}$ & 0.58 & 0.66 & 0.75 & 0.78 & 0.77 & 0.80 \\
\hline & $\begin{array}{l}\text { TWS + } \\
\text { SWAT }\end{array}$ & 0.62 & 0.68 & 0.74 & 0.77 & 0.77 & 0.79 \\
\hline
\end{tabular}
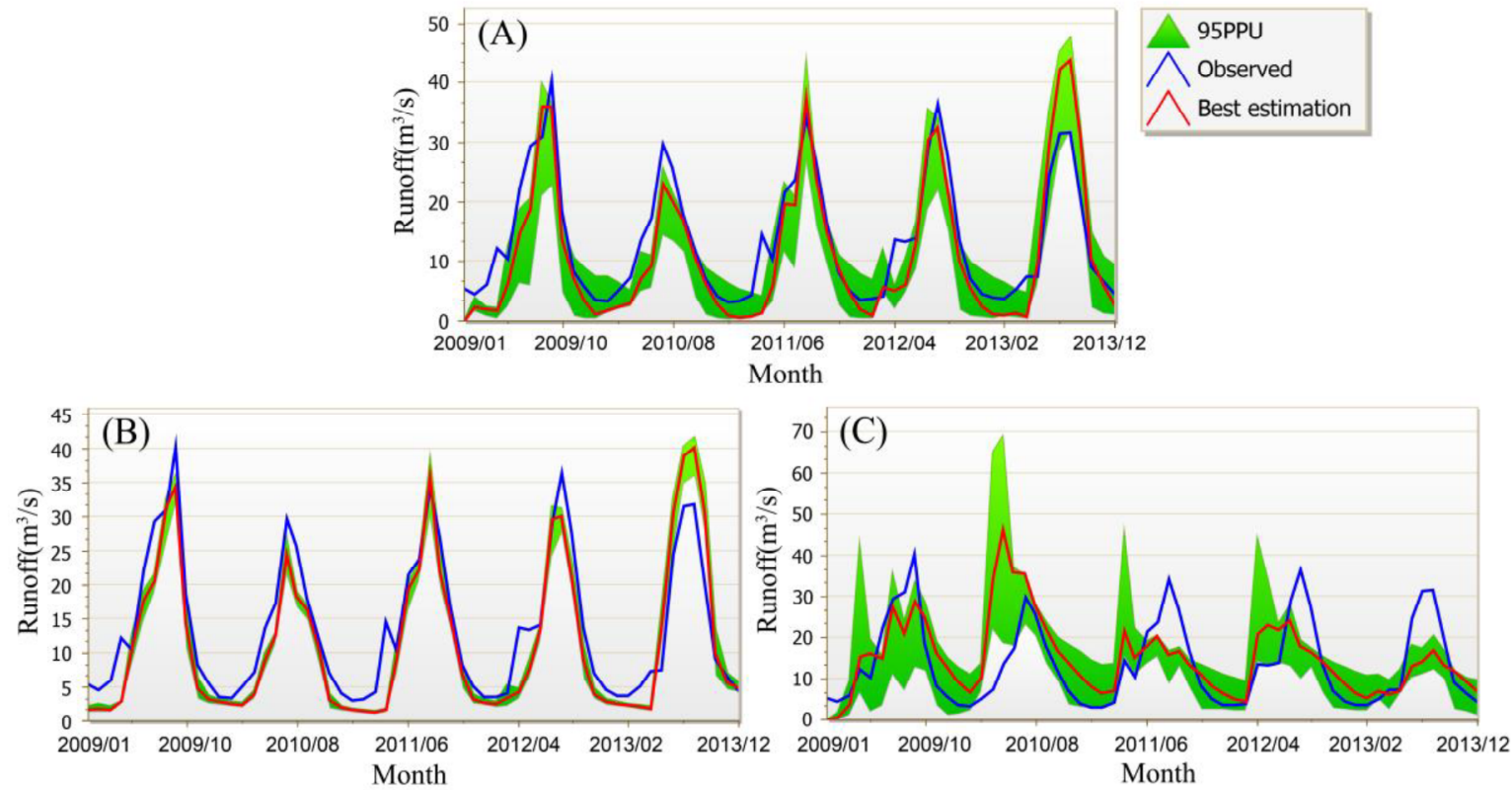

Figure 6. Simulation results of monthly average runoff by the three different modes at Qilian Mountain control station from 2009 to 2013: (A) CMADS + SWAT mode; (B) TWS + SWAT mode; (C) CFSR + SWAT mode.

We also found that the simulation results produced by the CFSR + SWAT mode were unsatisfactory at three stations. Relative to the observations, runoff was generally overestimated (although underestimated in summer), with the NSE efficiency coefficient reaching only 0.49 at maximum (Figure 6C, Figure 7C, and Figure 8C). Runoff overestimation was also present during the increasing runoff period from October to August in all three sub-basins. Each set of September simulation results was also underestimated by CFSR + SWAT. As the model overestimated the distribution of precipitation over the course of each year, the basin flow was also overestimated (Figure 6C, Figure 7C, and Figure 8C). This precipitation overestimation occurred because the CFSR data were not corrected against observed data obtained from meteorological stations. Although runoff was simulated well following model parameter calibration, the CFSR + SWAT mode tended to overestimate precipitation (Figure 4), possibly because it underestimated maximum temperature (Figure 5). The overestimation 
of CFSR precipitation caused the CFSR + SWAT-modeled evaporation to significantly exceed local annual evaporation following calibration.
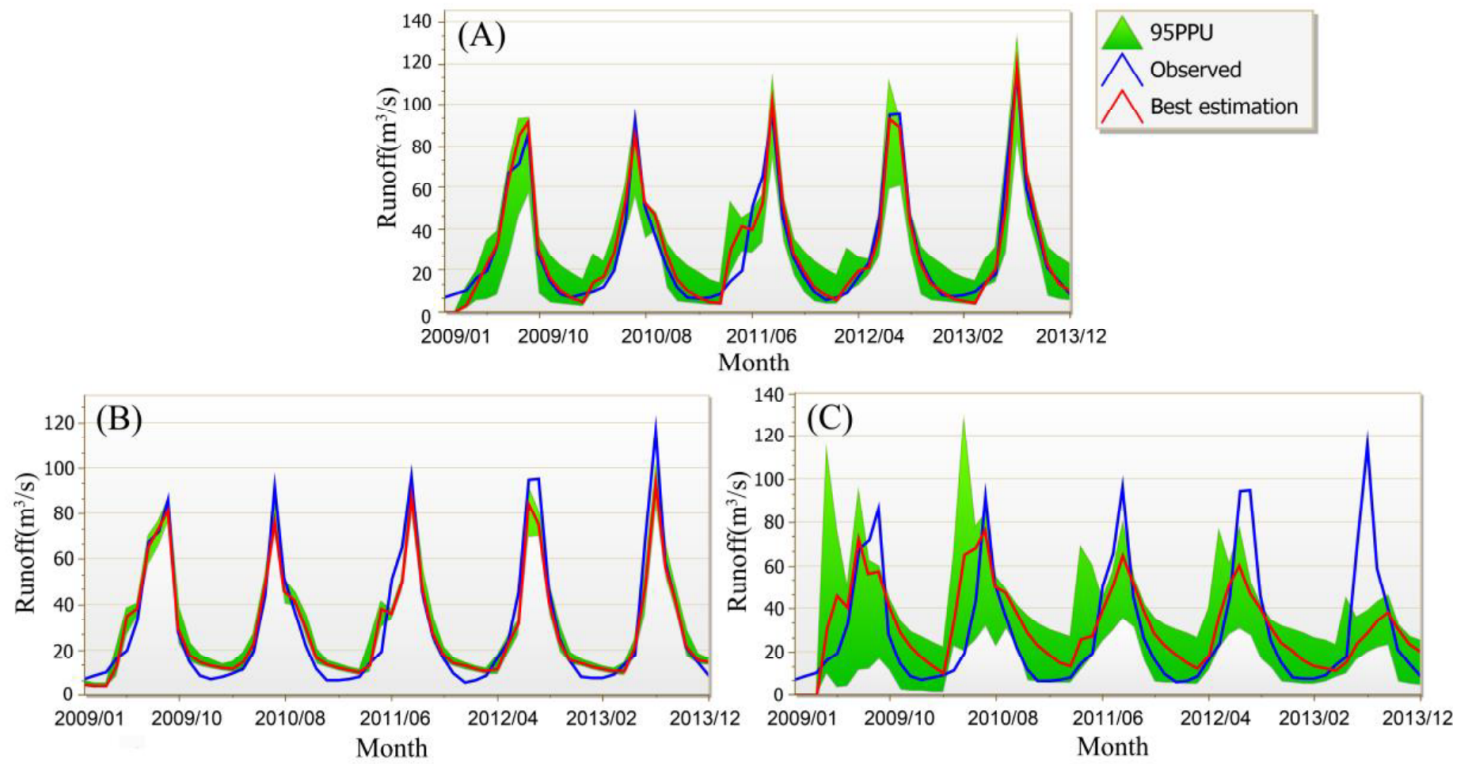

Figure 7. Simulation results of monthly average runoff by the three different modes at ZhaMashenke control station from 2009 to 2013: (A) CMADS + SWAT mode; (B) TWS + SWAT mode; (C) CFSR + SWAT mode.
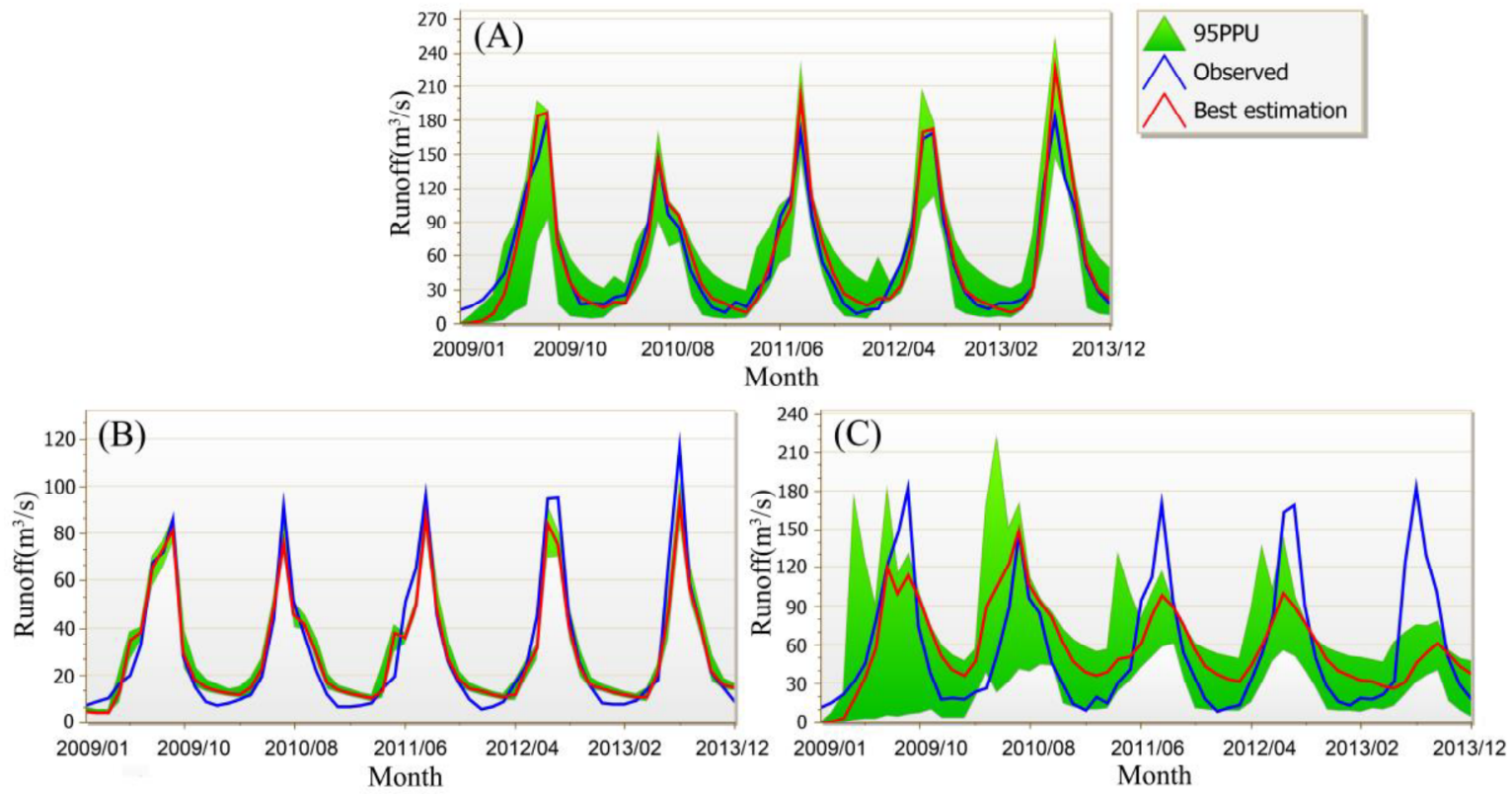

Figure 8. Simulation results of monthly average runoff by the three different modes at Ying Luoxia control station from 2009 to 2013: (A) CMADS + SWAT mode; (B) TWS + SWAT mode; (C) CFSR + SWAT mode.

On the monthly scale, we found that the observed runoff fell within 95PPU when the SWAT model was driven by CMADS. Compared with the Qilian Mountain control station (Figure 6), the P-factors of ZhaMashenke control station (Figure 7), and Ying Luoxia Control Station (Figure 8) are more obvious. Only part of the measured runoff value fell within the range of 95PPU when the SWAT model was driven by TWS. There was a large deviation between the observed runoff and the 95PPU driven by CFSR. We believe that this was due to the over-estimation of CFSR precipitation. From the best 
simulation point of view, CMADS-driven runoff perfectly reproduced the observed results (Figure 7A) at ZhaMashenke control station, while TWS was slightly underestimated (Figure 7B). Additionally, compared to CFSR's best simulation (Figure 6C, Figure 7C, and Figure 8C), CMADS and TWS showed good simulation performances at the three stations. Overall, we found that CMADS outperformed TWS in terms of uncertainty, and CFSR performed worst. In the best simulation, CMADS data was slightly better than TWS, and the CFSR performance was the worst.

Following monthly-scale calibration in the three sub-basins (Figures 6-8), the optimal parameters were applied to the SWAT model for continued calibration and adjustment of the three modes on a daily scale. As with the monthly simulation, both CMADS + SWAT and TWS + SWAT performed well at a daily scale (Table 5, Figures 9-11). The runoff simulation results produced by these modes were quite consistent with the daily hydrological maps for the three stations. By contrast, the simulated peak values at Qilian Mountain (Figure 9B) and ZhaMashenke (Figure 10B) produced by the TWS + SWAT mode were underestimated, while the peak at Ying Luoxia was slightly overestimated. Meanwhile, the simulated daily CMADS + SWAT results at Qilian Mountain $\left(N S=0.58, R^{2}=0.66\right)$ were both acceptable, and the model also performed satisfactorily at Ying Luoxia $\left(N S=0.77, R^{2}=0.80\right)$ and ZhaMashenke $\left(N S=0.75, R^{2}=0.78\right)$. The March-April simulated daily results at ZhaMashenke produced by CMADS + SWAT were higher and had larger amplitude than the observed results; however, the model's simulation results were better than those produced by the TWS + SWAT mode during other periods. The peak simulation accuracies of CMADS + SWAT at Qilian Mountain and ZhaMashenke exceeded those produced by either the TWS + SWAT or CFSR + SWAT modes. Overall, the CMADS + SWAT mode simulations agreed more closely with the observed data than those produced by the other two modes, particularly at the Qilian Mountain and ZhaMashenke control stations. These results indicate that CMADS data can effectively capture spatial heterogeneity that is missed when a limited number of conventional meteorological stations is used, a factor that limits the applicability of TWS to simulating basin water balance.
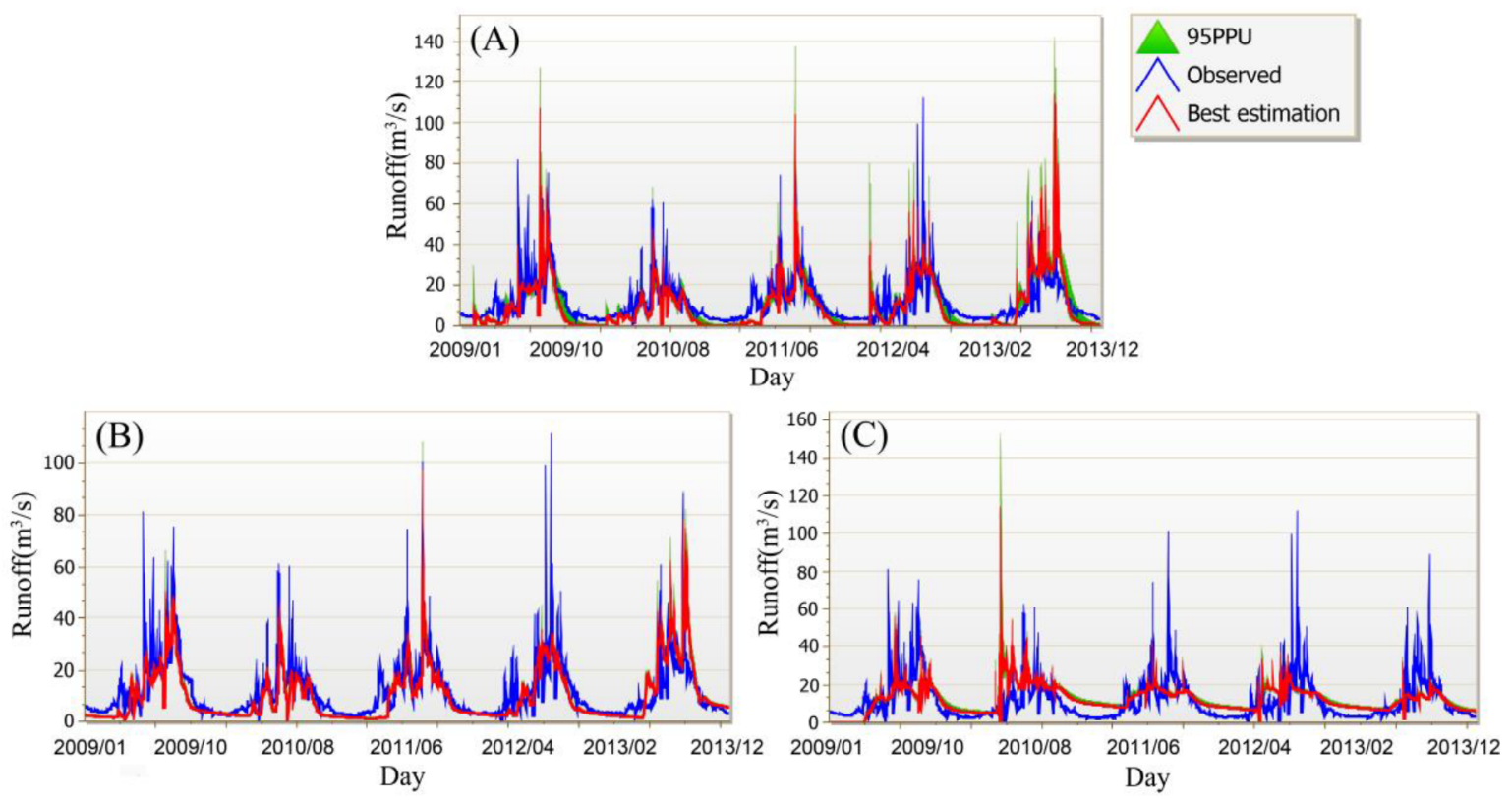

Figure 9. Daily runoff simulation results of three different modes at Qilian Mountain control station from 2009 to 2013: (A) CMADS + SWAT mode; (B) TWS + SWAT mode; (C) CFSR + SWAT mode. 

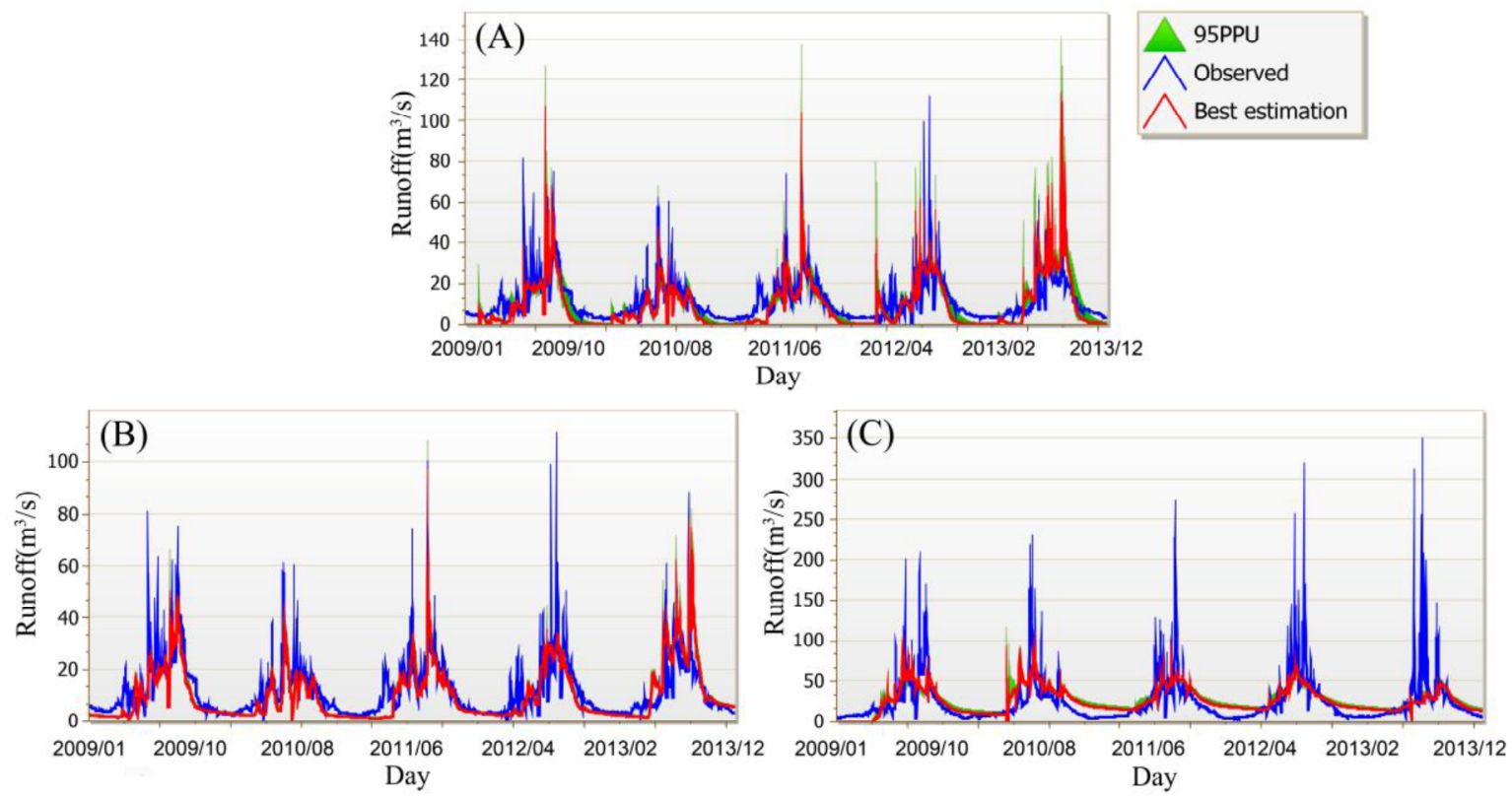

Figure 10. Daily runoff simulation results of three different modes at ZhaMashenke control station from 2009 to 2013: (A) CMADS + SWAT mode; (B) TWS + SWAT mode; (C) CFSR + SWAT mode.
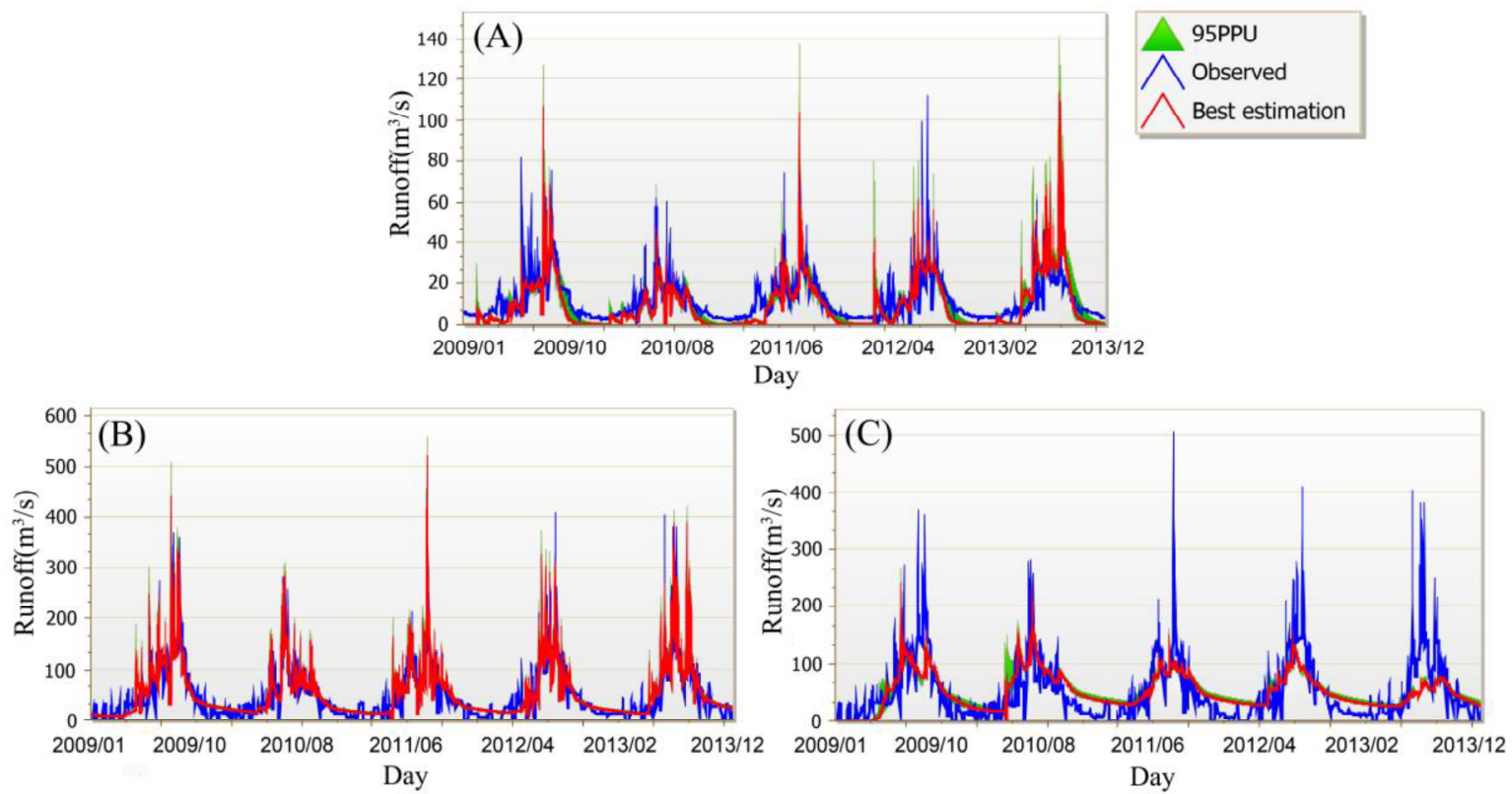

Figure 11. Simulation results of monthly average runoff of three different modes at Ying Luoxia control station from 2009 to 2013: (A) CMADS + SWAT mode; (B) TWS + SWAT mode; (C) CFSR + SWAT mode.

The interval range of 95PPU on the daily scale was significantly smaller than that on the monthly scale. This phenomenon was observed at all three hydrological control stations (Figures 9-11). However, similar to the monthly scale, the measured runoff value driven by CMADS basically fell within the range of 95PPU, followed by that driven by TWS and CFSR. From the best simulation, the performance of CMADS and TWS was similar, and the CFSR simulation results and observations show great errors (Figures 9-11).

Our comparison of the monthly-scale and daily-scale simulation results produced by a SWAT model driven by three types of datasets (TWS, CSFR, and CMADS) reveals that CMADS + SWAT can simulate historical HRB runoff processes much better than the widely used CFSR dataset (see Table 5). 


\subsection{Five-Year Monthly-Scale Runoff Simulation Results for Three Sub-Basins}

Following parameter calibration, the water yield (WYLD) produced by the CFSR + SWAT mode reached a level similar to that produced by the other modes. However, the CFSR precipitation element was reflected in only a few large-scale precipitation modes. Similar to the results shown in Figure 12A, the CFSR + SWAT mode runoff result reached a peak consistency in July but was generally inconsistent with observation in other periods. In Figure 12, it can be seen that CFSR + SWAT overestimated during periods of rising (Jan-Jun) and declining (Oct-Dec) runoff and also overestimated annually between July and September.
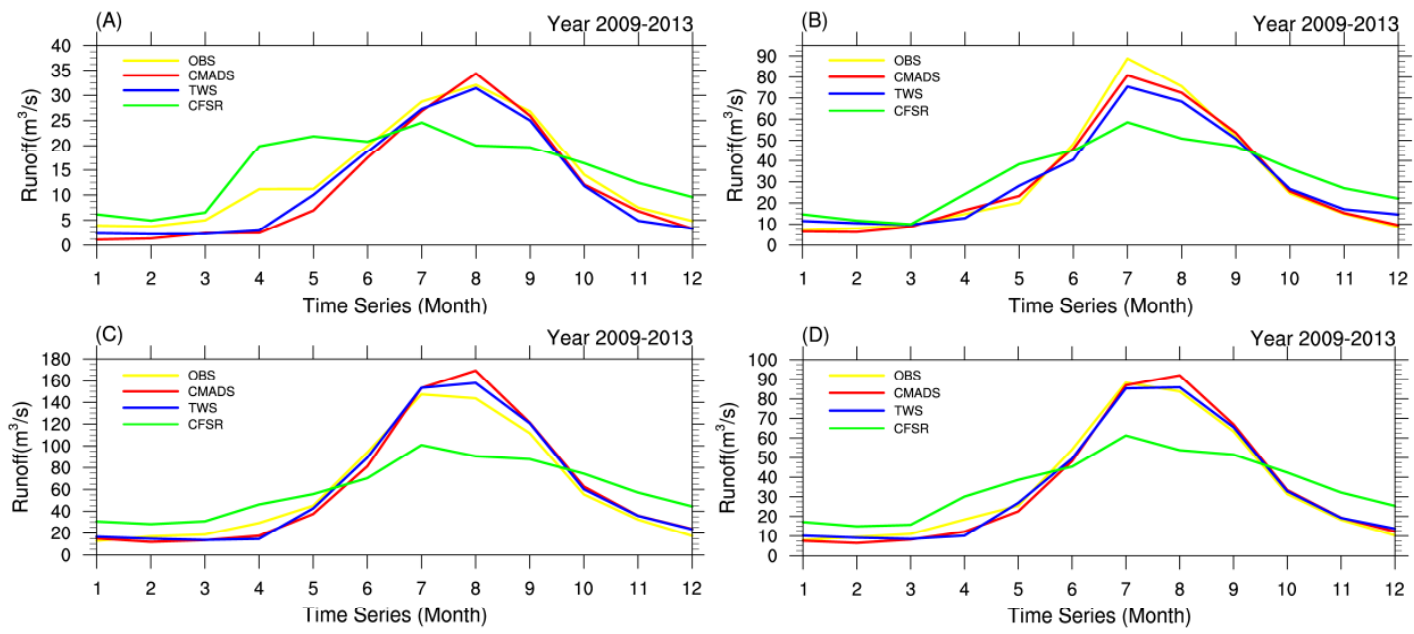

Figure 12. Comparison between five-year average monthly runoff (2009-2013) simulated results from three different modes (TWS + SWAT, CFSR + SWAT, and CMADS + SWAT) and observed values at

(A) Qilian Mountain Sub-basin, (B) ZhaMashenke Sub-basin, (C) Ying Luoxia Sub-basin, and for the (D) average basin value.

Figure 12A,C,D shows that both the TWS + SWAT and CMADS + SWAT modes slightly underestimated between March and May (a rising runoff period).

Compared to the CMADS + SWAT mode, TWS + SWAT produced a slight underestimation in November (a declining runoff period). In general, both TWS + SWAT and CMADS + SWAT closely reproduce the monthly average peak value of runoff observation. The TWS + SWAT mode overestimated for January, April-May, and October-December and produced significant underestimates for mid-May through September.

However, although CFSR datasets overestimated precipitation, this phenomenon was not seen for runoff in July. We found that CFSR runoff was underestimated in June-September, whereas runoff was nearly overestimated in other months of the year. However, CMADS and TWS did not show this phenomenon. We believe that the precipitation of CFSR was overestimated in early spring, when snowmelt occurs, which led to further overestimation of runoff, and further affected the calibration process of the summer (July-August) model. This shows that the model error caused by precipitation from CFSR data is positive.

\subsection{Differences Caused by Water Balance}

Water balance analysis is an important tool in evaluating water resources and can aid in differentiating the quality of various forcing data [34,41]. Our analysis of the water balance components in the HRB produced using the three modes reveals that using overestimated CFSR precipitation as an input to the SWAT model leads to higher amounts of evaporation and estimated water balances than under the other two datasets (Figure 13). 


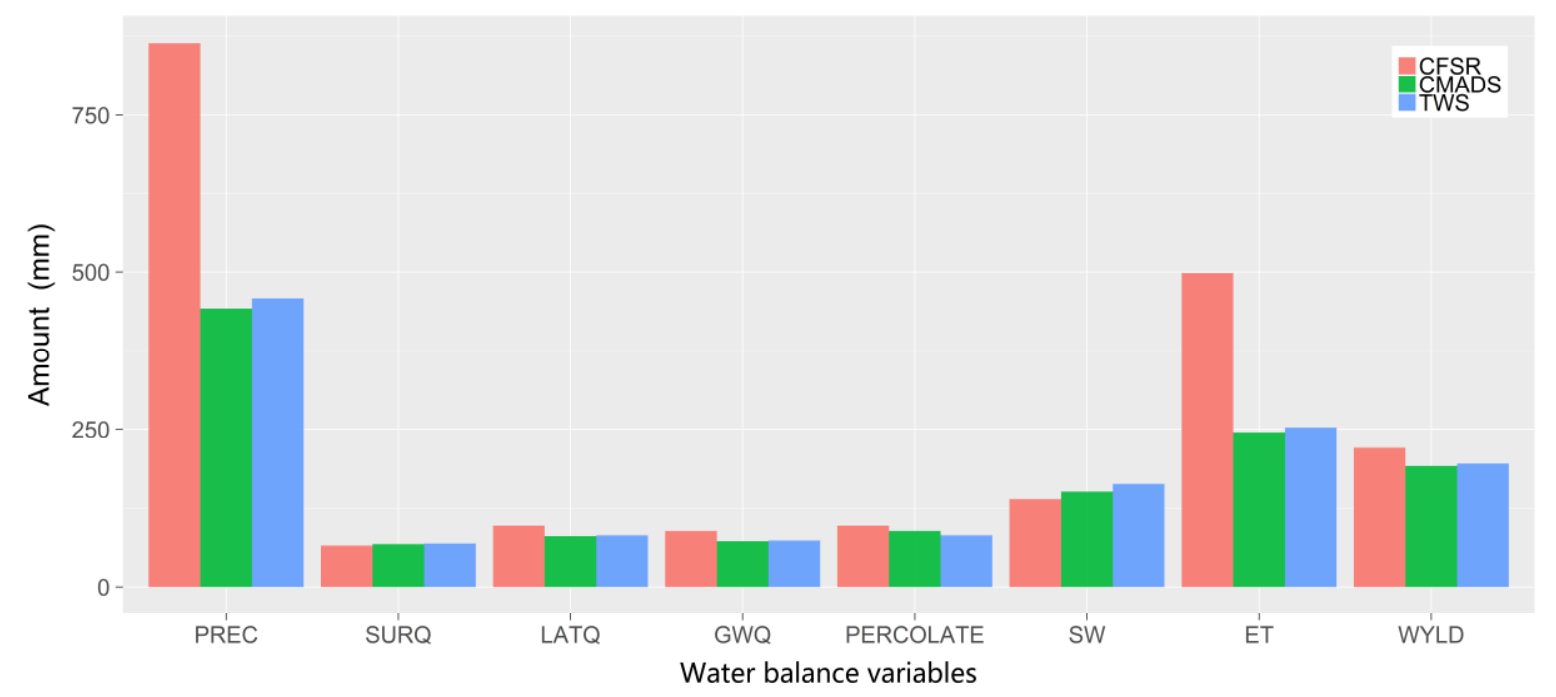

Figure 13. Water balance chart in Heihe River Basin (HRB) for the three modes (TWS + SWAT, CFSR + SWAT, and CMADS + SWAT), where PREC, SURQ, LATQ, GWQ, PERCOLATE, SW, ET, and WYLD represent precipitation, surface runoff, lateral flow, return flow, percolation to shallow aquifer, soil water, evaporation and transpiration, and water yield, respectively.

From Figure 13 it can be seen that the precipitation distribution in the basin produced by CFSR was much higher than that produced by the other two datasets, with an average annual precipitation of $864.35 \mathrm{~mm}$, compared to those from CMADS and TWS, at 442.45 and $458.48 \mathrm{~mm}$, respectively. Previous studies have shown that the annual precipitation in the main stream area of the Heihe River is $459.7 \mathrm{~mm}$ [80], a figure consistent with the overestimated precipitation produced by CFSR. The TWS + SWAT and CMADS + SWAT modes respectively partitioned $42.6 \%$ and $43.3 \%$ of precipitation into runoff, while the CFSR + SWAT mode partitioned only $25.5 \%$ into runoff. We also found that the proportions of side, subsurface, and lateral seepage flow during the runoff generation period were higher with CFSR + SWAT (44.2\%, 39.9\%, and 44.17\%, respectively) than with the other modes.

The overestimated precipitation produced by CFSR + SWAT also resulted in reduced soil moisture relative to the other modes, possibly because of the high amount of evaporation occurring under the CFSR + SWAT mode. By contrast, the actual evapotranspiration produced by the CFSR + SWAT mode was much larger than that by the other two modes (the annual average evapotranspiration under the CFSR + SWAT mode was $498.27 \mathrm{~mm}$, compared to 245.18 and $253.09 \mathrm{~mm}$ under CMADS + SWAT and TWS + SWAT, respectively). Actual measurements reveal that the annual average evapotranspiration in the Heihe River mountain and main stream areas is approximately 279.3-294.1 mm [80]. It appears that fitting the water balance produced by CFSR + SWAT to observed runoff caused it to overestimate precipitation, which in turn led to increased evaporation and reduced soil moisture. Thus, although the water balance with CFSR + SWAT was similar to those under the other two modes, its poor performance in simulating evaporation and precipitation significantly decreased the accuracy of CFSR in modelling the HRB.

To refine the performance of the three modes with the goal of better reproducing seasonal water balance changes, the change in seasonal distribution of the overall water balance in the HRB over the course of a year was extracted for each mode (Figure 14). 


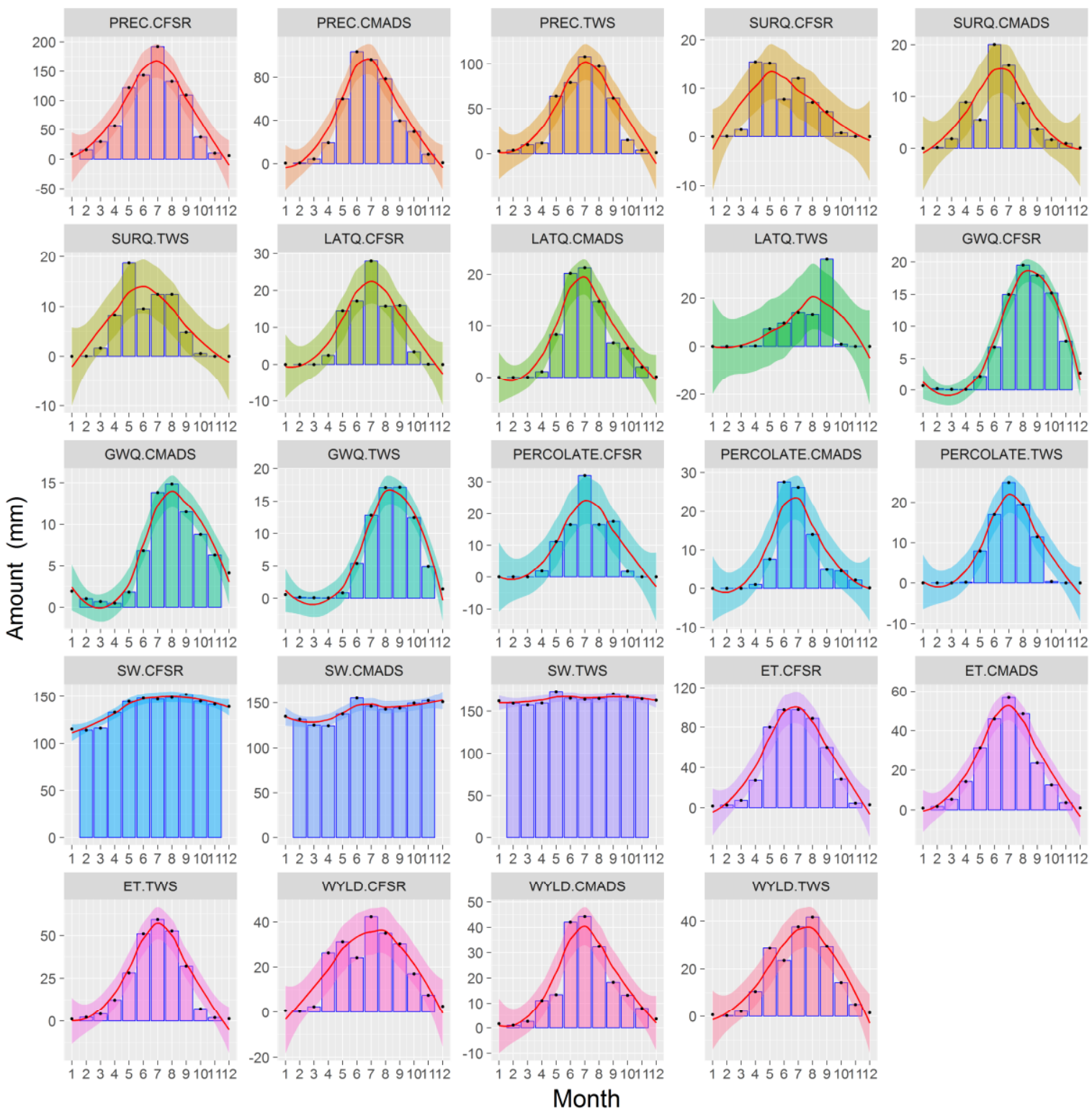

Figure 14. Seasonal Water balance chart in Heihe River Basin (HRB) of the three modes (TWS + SWAT, CFSR + SWAT and CMADS + SWAT), where PREC, SURQ, LATQ, GWQ, PERCOLATE, SW, ET, and WYLD represent precipitation, surface runoff, lateral flow, return flow, percolation to shallow aquifer, soil water, evaporation and transpiration, and water yield, respectively.

Analyses of the respective water balance evolutions revealed that the surface runoff (SURQ), water yield (WYLD) and precipitation (PREC) produced by each mode were consistent (Figure 14) and correlate well with the average monthly runoff (Figure 13) and precipitation distribution (Figure 15) within different sub-basins. A more in-depth assessment revealed that, although the annual distributions of precipitation and evaporation were similar, the total precipitation and evaporation components produced by CFSR + SWAT were significantly higher than those by the other two modes. In terms of magnitude, the CMADS + SWAT and TWS + SWAT results were fairly similar to the actual data, with the results produced by CMADS + SWAT lower than those produced by TWS + SWAT. The modelling also successfully reproduced the annual water balance in the basin (Figure 13). 

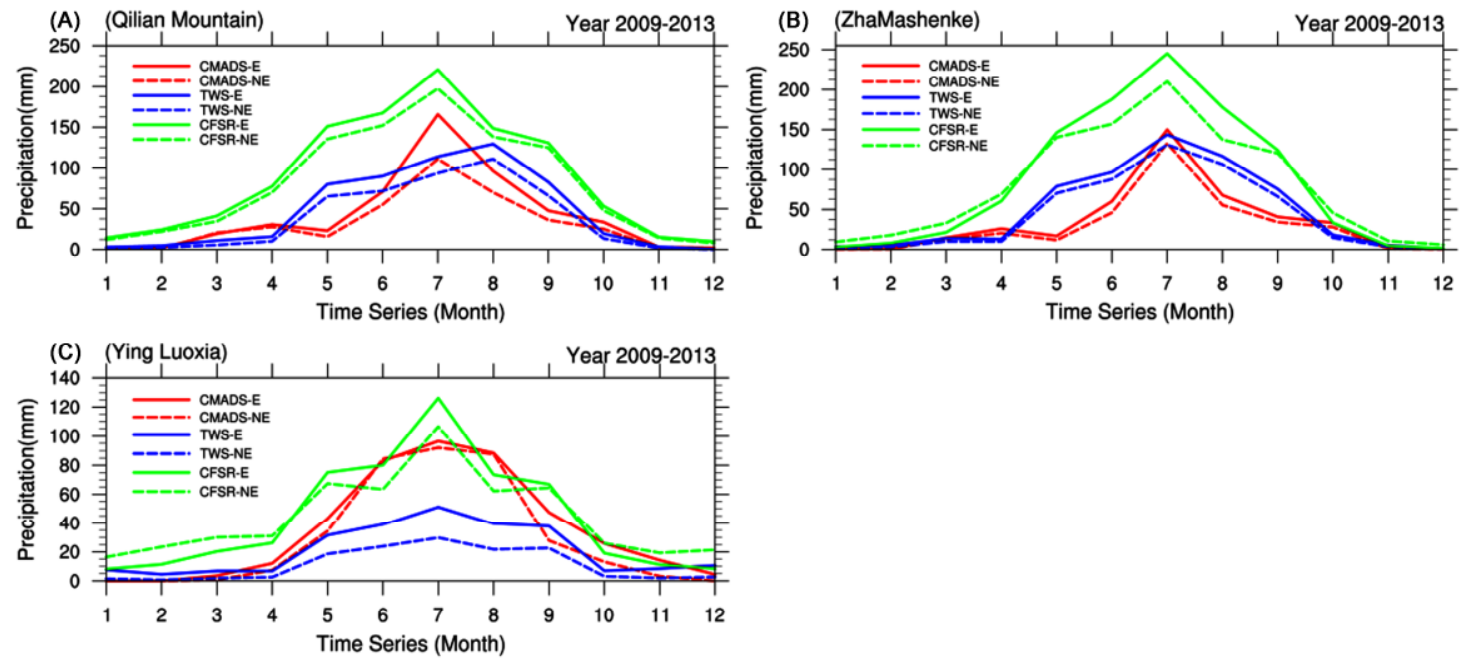

Figure 15. Precipitation distribution of CMADS, CFSR, and TWS dataset with (-E) and without (-NE) the elevation module at (A) Qilian Mountain, (B) ZhaMashenke, and (C) Ying Luoxia stations.

In terms of surface runoff components, the CFSR + SWAT mode overestimated the overall watershed results during April of each year, whereas the other two models (CMADS + SWAT and TWS + SWAT mode) produced results closer to the actual April values.

The overall HRB reaches a peak surface runoff from June to August. Whereas the CMADS + SWAT mode perfectly reproduced the peaking characteristics of the basin, the TWS + SWAT mode could not reproduce the peaking from June to August. As with the surface runoff results, CMADS + SWAT could, unlike the other modes, perfectly reproduce the lateral flow (LATQ), return flow (GWQ), and percolation to shallow aquifer (PERCOLATE) components. In terms of soil water content (SW), CFSR + SWAT and CMADS + SWAT produced highly fluctuating peaks and valleys, whereas TWS + SWAT produced smoother results. Melting processes occurring in the HRB in March cause the soil moisture content of the basin to rise steeply, with a maximum occurring during the precipitation peak from June-August. The performance of the TWS + SWAT mode is inferior compared to both CMADS + SWAT and CFSR + SWAT in simulating the seasonal changes in soil moisture content. Overall, the CMADS + SWAT mode has a greater ability to reproduce water balance than the other two modes. Seasonal water balance analysis is important because these changes are complex; the meteorological conditions (such as air temperature, precipitation, humidity, etc.) and the distribution of surface soil and land cover are changing. For example, in April, CMADS precipitation is higher than that in March, while soil moisture is slightly lower. From June to July each year, TWS precipitation reaches its peak, whereas soil moisture of TWS is lower than that in May. The former may be attributed to the freezing of soil water weight caused by the melting of snow in the basin, and the latter may be attributed to vegetation transpiration and soil evaporation in July.

From the overall point of view of water balance, CMADS and TWS have similar spatial distribution patterns and are similar in terms of order of magnitude, whereas CFSR datasets exhibit larger deviations from TWS. This is due to the deviation in precipitation. In the process of model calibration, model parameters and uncertainties differ in three ways because of the great differences in the methods. The SWAT model driven by CFSR exhibits more errors than do the other modes. Since precipitation is an important factor in distinguishing the characteristics of the above three products, we focus on a comparative analysis of precipitation elements below.

Precipitation is an important factor controlling watershed runoff processes. To assess the ability of the SWAT-driven CMADS dataset to reflect the real conditions in the HRB, a bias calculation of the precipitation distribution generated by the SWAT model across the three sub-basins was conducted (Figure 16). 


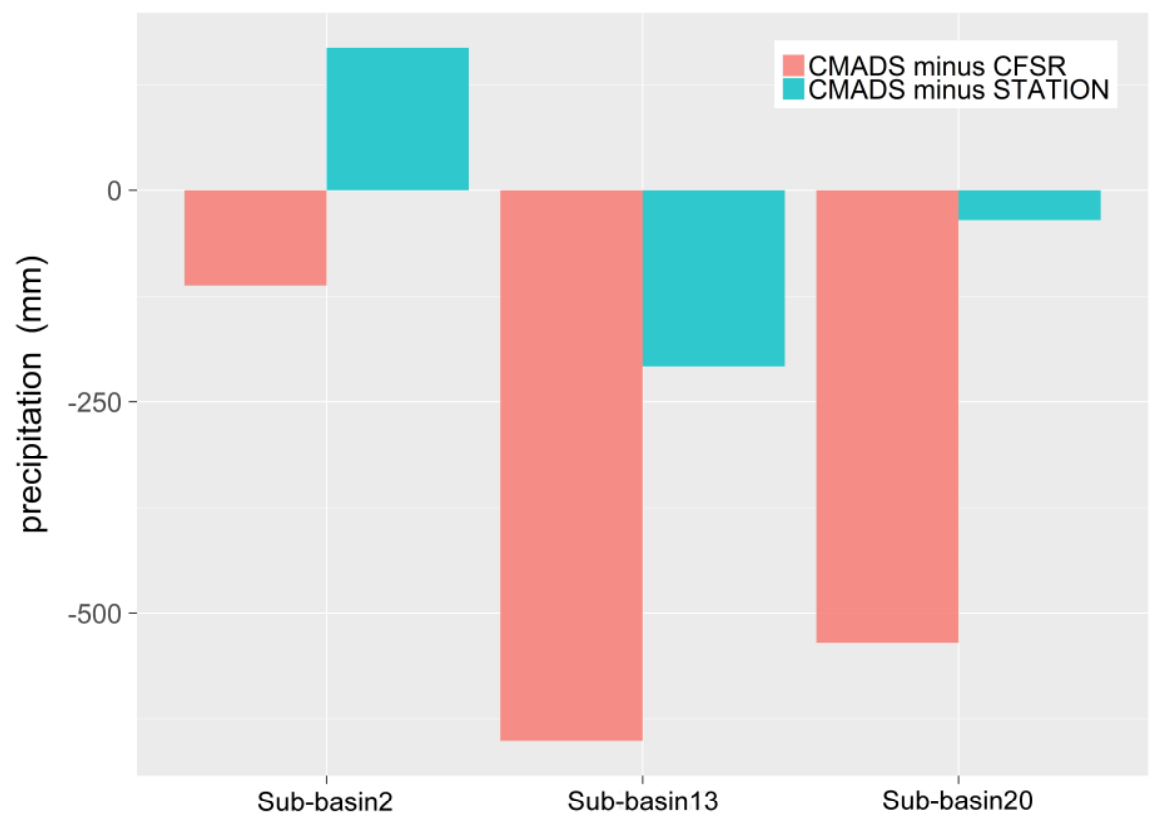

Figure 16. Bias distribution of annual average precipitation of CMADS, CFSR, and TWS datasets in different sub-basins.

It was found that the average annual precipitation produced by CMADS + SWAT exceeded that produced by TWS + SWAT only in the Ying Luoxia basin, and was smaller than the precipitation produced by the other modes in the remaining sub-basins. In the datasets, precipitation was obtained via elevation correction and barycenter interpolation of the SWAT model. Due to a lack of observed data, it was difficult to judge which model produced the most reliable precipitation, which thus had to be judged using other methods.

To quantitatively investigate how the SWAT model's built-in elevation module affects precipitation distribution, we analyzed precipitation results for the three sub-basins (Sub-basin 20-Qilian Mountain, Sub-basin 13-ZhaMashenke, and Sub-basin 2-Yingluoxia) with and without the elevation module applied (Figure 15). Since we only obtained observational data (especially runoff data) for these three sub-basins, we believe that the analysis of these three typical sub-basins will be more representative and credible. After analysis, we found some consistent relations between precipitation distribution (Figure 15) and the previous water balance (Figures 13 and 14). The precipitation produced by the CFSR dataset exceeded that by both the TWS and CMADS datasets, with values of 526.42, 1012.982, and $1053.66 \mathrm{~mm}$ for the respective sub-basins, which significantly exceeds the local multi-annual average precipitation $(459.7 \mathrm{~mm})$ [79]. An examination of Figure 16 reveals more concentrated precipitation peak values for CFSR and CMADS than for TWS, particularly in the Qilian Mountain basin (Figure 15A).

Application of the elevation module to the SWAT model resulted in somewhat of an increase in precipitation, particularly around July. The precipitation produced by the CMADS + SWAT mode in Ying Luoxia between May and September was approximately 39.7\% higher than that by TWS + SWAT (Figure 15), resulting in a larger overestimation of the monthly runoff under the former model. However, the daily runoff simulation $\mathrm{R}^{2}$ value of 0.8 from the CMADS + SWAT mode exceeded that produced by the TWS + SWAT mode (Table 5). It was also determined that, for weather stations located a long distance from a hydrological station or in areas lacking in weather stations, the CMADS + SWAT mode achieved better results. It is also seen from Figure 15B that less precipitation was produced by CMADS + SWAT than by TWS + SWAT between April and June and August and October. Furthermore, the fit between simulated and actual peak values and base flows produced by the CMADS + SWAT mode for the ZhaMashenke Sub-basin (Figures 7A and 10A) were superior to those produced by TWS + SWAT (Figure 7B, Figure 10B, and Figure 14B and Table 5). The simulation results produced by the CMADS + SWAT and TWS + SWAT modes for the Qilian Mountain Sub-basin were both satisfactory. 
Overall, the CFSR shows precipitation over-estimation in most seasons in the HRB. This phenomenon is particularly evident in April-October of each year, and precipitation over-estimation peaks in July of each year. The application of the elevation module to the SWAT model makes the over-estimation more obvious, wherein the estimated trend is an increasing trend in overestimation. This affects the output of the model to a large extent and is directly reflected in the water balance. Compared to the results of CFSR, when CMADS and TWS drive the SWAT model, the precipitation results are more similar. As TWS is the observation data, we believe that CMADS is closer to the real precipitation situation in the HRB, and the error from the SWAT model driven by TWS and CMADS is much smaller than that driven by CFSR.

\section{Conclusions}

Here, CMADS, TWS, and CFSR datasets were used to force a SWAT model. The performances of the respective combined models in simulating streamflow in the HRB were then compared. It was found that CFSR overestimated precipitation, particularly in summer. As it applies advanced assimilation technology (STMAS) and is bias-corrected using data from China's national automatic observation stations, the CMADS dataset outperformed CFSR in terms of both accuracy and spatial resolution. TWS was found to perform poorly, particularly in Western China, where climate stations are sparse. The quantitative analysis of water balance components is essential in supporting the ecological and hydrological management of large river basins. As TWS data often cannot satisfy large-scale hydrological modelling requirements in regions with sparse observation stations, CMADS can be a valuable resource for obtaining atmospheric forcing data for hydrological modelling exercises.

Overall, the main conclusions of this paper are as follows:

1. With regard to the accuracy of meteorological data, the results obtained using the CMADS dataset generally match observations obtained at automatic stations in China. The goodness of fit between CMADS and TWS was better than that between CFSR and TWS.

2. The runoff results obtained by the CMADS-driven SWAT model almost perfectly reproduce historical runoff data. This excellent performance is not only reflected in the runoff simulation evaluation indicators, but also found through the analysis of 95PPU. CMADS outperforms TWS in terms of uncertainty, and CFSR performs worst. In the best simulation, CMADS data is slightly better than TWS, and CFSR performance is the worst. This excellent performance by CMADS is similar on both monthly and daily scales, while CFSR shows poor simulation ability due to the overestimation of summer precipitation.

3. The CMADS + SWAT mode has a greater ability to reproduce water balance than the other two modes. However, because of the complexity of surface processes in the basin, further investigation is needed.

4. Overestimation of CFSR precipitation results in a greater error impact on the uncertainty output of the model, whereas the performances of CMADS and TWS are more similar when driving the SWAT model.

Author Contributions: Conceptualization, X.M. and H.W.; Investigation, M.X.; Writing-original draft preparation, X.M.; Writing—review and editing, Y.W., M.Y. and X.Z.; Supervision, J.C.; Funding acquisition, Z.P.

Funding: This research was financially supported by the National Science Foundation of China (41701076) and the national key R\&D program (No. 2018YFA0606303) of China.

Conflicts of Interest: The authors declare no conflict of interest. 
Abbreviations

HRB

SWAT

CMADS

CFSR

TWS

CMADS+SWAT

CFSR+SWAT

TWS+SWAT

NCEP

NCAR

ECMWF

ERA-Interim

ERA-15

ERA-40

MERRA

NASA

EnKF

IFS

MOM4

3DVAR

GODAS

GLDAS

GEOS-5

ADAS

GIS

$\mathrm{SiB}$

JRA-25

JMA

JCDAS

SAC-SMA

TRMM

IPCC

GCMs

MC2

RegCM3

CGIAR

CGIAR-CSI

HRUs

GLC2000

WestDC

MEDW

BROM

ROCK

ICE

DEGA

AGRL

FRSD

GRAV

RNGB

DESE

PAST

DEM
Heihe River Basin

Soil and Water Assessment Tool

China Meteorological Assimilation Driving Datasets for the SWAT model

Climate Forecast System Reanalysis

Traditional meteorological Station

SWAT Model Driven by CMADS

SWAT Model Driven by CFSR

SWAT Model Driven by TWS

National Centers for Environmental Prediction

National Center for Atmospheric Research

European Centre for Medium-Range Weather Forecast

ECMWF Reanalysis-Interim

ECMWF Reanalysis-15

ECMWF Reanalysis-40

Modern Era Retrospective-Analysis for Research and Applications

National Aeronautics and Space Administration

Ensemble Kalman Filter

Integration Forecasting System

Modular Ocean Model Version 4

Three-Dimensional Variational Data Assimilation

Global Ocean Data Assimilation System

Global Land Data Assimilation System

Goddard Earth Observing System, Version 5

Atmospheric Data Assimilation System

Geographic Information System

Simple Biosphere Mode

Japanese 25-year ReAnalysis

Japan Meteorological Agency

JMA Climate Data Assimilation System

Sacramento Soil Moisture Accounting Model

Tropical Rainfall Measuring Mission

Intergovernmental Panel on Climate Change

Global Climate Models

Mesoscale Community Compressible

Regional Climate Model, version 3

Consultative Group on International Agricultural Research

CGIAR Consortium for Spatial Information

Hydrological Response Units

Global Land Cover Database for the year 2000

China West Data Centre

Meadow

Meadow Bromegrass

Bare Rocks

Ice

Desert Grassland

Farmland

Needle-leaved Deciduous Forest

Bravels

Bush

Desert

Plain Grassland

Digital Elevation Model 


$\begin{array}{ll}\text { SCS } & \text { Soil Conservation Service } \\ \text { SUFI-2 } & \text { Sequential Uncertainty Fitting } \\ \text { 95PPU } & 95 \% \text { prediction uncertainty } \\ \text { CN2.mgt } & \text { SCS runoff curve value } \\ \text { ALPHA_BF.gw } & \text { Baseflow factor } \\ \text { GW_DELAY.gw } & \text { Delay time (day) of aquifer replenishment } \\ \text { GWQMN.gw } & \text { Water level threshold (mm) of shallow aquifer when groundwater flowing into } \\ \text { GW_REVAP.gw } & \text { the main river channel } \\ \text { ESCO.hru } & \text { Evaporation coefficient of groundwater } \\ \text { ALPHA_BNK.rte } & \text { Compensation factor of soil evaporation } \\ \text { SFTMP } & \text { Recession constant value of base flow } \\ \text { PLAPS } & \text { Average temperature (;æ) at snowing days } \\ \text { SMFMN } & \text { Lapse rate of precipitation } /(\mathrm{mm} ; \mathrm{km}-1) \\ \text { SMFMX } & \text { Snowmelt factor at } 21 \text { December } / \mathrm{mm} ; \mathrm{a}(\text { day-iæ)-1 } \\ \text { TLAPS } & \text { Snowmelt factor at } 21 \text { June } \\ \text { NSE } & \text { Lapse rate of temperature } \\ \text { R2 } & \text { Nash-Sutcliffe Efficiency } \\ \text { PREC } & \text { Determination Efficiency } \\ \text { SURQ } & \text { Precipitation } \\ \text { LATQ } & \text { Land surface runoff } \\ \text { GWQ } & \text { Side flow } \\ \text { PERCOLATE } & \text { Subsurface flow } \\ \text { SW } & \text { Lateral seepage flow } \\ \text { ET } & \text { Soil water } \\ \text { WYLD } & \text { Actual evaporation } \\ & \text { Runoff } \\ & \end{array}$

\section{References}

1. Collick, A.S.; Easton, Z.M.; Ashagrie, T. A simple semi-distributed water balance model for the Ethiopian highlands. Hydrol. Process. 2009, 23, 3718-3727. [CrossRef]

2. Lyu, H.M.; Shen, L.S.; Yang, J.; Yin, Z.Y. Scenario-based inundation analysis of metro systems: A case study in Shanghai. Hydrol. Earth Syst. Sci. Discuss. 2019. In review. [CrossRef]

3. Kim, U.; Kaluarachchi, J.J.; Smakhtin, V.U. Generation of monthly precipitation under climate change for the Upper Blue Nile River Basin, Ethiopia. J. Am. Water Resour. Assoc. 2008, 44, 1231-1247. [CrossRef]

4. Muluneh, A.M.; Anders, W.; Bijan, D. Hydrological modelling of Ethiopian catchments using limited data. Hydrol. Process. 2009, 23, 3401-3408.

5. Assefa, M.M.; Wossenu, A.; Tibebe, D.; Wang, X. Low and high flow analyses and wavelet application for characterization of the Blue Nile River system. Hydrol. Process. 2010, 252, 241-252.

6. Neitsch, S.L.; Arnold, J.G.; Kiniry, J.R. Soil and Water Assessment Tool Theoretical Documentation, version 2005; Grassland Soil and Water Research Laboratory, Agricultural Research Service, Blackland Research Center, Texas Agricultural Experiment Station: Temple, TX, USA, 2012.

7. Zhang, Q.; Heiner, K.; Karin, H. How well do reanalyses represent the southern African precipitation? Clim. Dyn. 2013, 40, 951-962. [CrossRef]

8. NCEP Climate Forecast System Reanalysis (CFSR) Selected Hourly Time-Series Products, January 1979 to December 2009. Available online: https://rda.ucar.edu/datasets/ds093.1/docs/CFSR--Hourly-Timeseries.pdf (accessed on 2 December 2010).

9. Trenberth, K.E.; Anthes, R.A.; Belward, A. 2013 Challenges of A Sustained Climate Observing System; Springer: Berlin, Germany.

10. Saha, S.; Nadiga, S.; Thiaw, C.; Wang, J.; Wang, W.; Zhang, Q.; van den Dool, H.M.; Pan, H.-L.; Moorthi, S.; Stokes, D.; et al. The NCEP climate forecast system. J. Clim. 2006, 19, 3483-3517. [CrossRef]

11. Kanamitsu, M.; Ebisuzaki, W.; Woollen, J. NCEP-DEO AMIP-II reanalysis (R-2). Bul. Aymos. Met. Soc. 2002, 83, 1631-1643. [CrossRef] 
12. Dee, D.P.; Uppala, S.M.; Simmons, A.J. The ERA-Interim reanalysis: Configuration and performance of the data assimilation system. Q. J. R. Meteorol. Soc. 2011, 137, 553-597. [CrossRef]

13. Gibson, J.K.; Allberg, K.; Uppala, P.; Nomura, S. ERA description. In ECMWF ERA-15 Project Report Series, No.1; European Centre for Medium-Range Weather Forecasts: Shinfield, UK, 1997; Available online: www.ecmwf.int/publications (accessed on 1 January 1999).

14. Uppala, S.M.; Kllberg, P.W.; Simmons, A.J. The ERA-40 re-analysis. Q. J. R. Meteorol. Soc. 2005, 131, $2961-3012$. [CrossRef]

15. Rienecker, M.M. NASA's modern-era retrospective analysis for research and applications. J. Clim. 2011, 24, 3624-3648. [CrossRef]

16. Najafi, M.R.; Moradkhani, H.; Piechota, T.C. Ensemble streamflow prediction: Climate signal weighting methods vs. climate forecast system reanalysis. J. Hydrol. 2012, 442, 105-116. [CrossRef]

17. Fuka, D.R.; Walter, M.T.; MacAlister, C. Using the climate forecast system reanalysis as weather input data for watershed models. Hydrol. Process. 2014, 28, 5613-5623. [CrossRef]

18. Smith, R.A.; Kummerow, C.D. A comparison of in situ, reanalysis, and satellite water budgets over the Upper Colorado River Basin. J. Hydrometeorol. 2013, 14, 888-905. [CrossRef]

19. David, A.L.; Gabriele, V.; Richard, P.A.; Eric, F.W.; Andrew, J.W. The detection of atmospheric rivers in atmospheric reanalyses and their links to British winter floods and the large-scale climatic circulation. J. Geophys. Res. 2012, 117. [CrossRef]

20. Quadro, M.F.; Berbery, E.H.; Dias, M.A.F.S. The atmospheric water cycle over South America as seen in the new generation of global reanalyses. In AIP Conference Proceedings; American Institute of Physics: College Park, MD, USA, 2013; Volume 732, pp. 732-735.

21. Wu, W.; Chen, J.L.; Huang, R.H. Water budgets of tropical cyclones: Three case studies. Adv. Atmos. Sci. 2013, 30, 468-484. [CrossRef]

22. Takacs, L.L.; Molod, A.; Wang, T. Documentation of the Goddard Earth Observing System (GEOS) General Circulation Model; version 1; NASA Technical Memorandum: Washington, DC, USA, 1994. Available online: https://gmao.gsfc.nasa.gov/pubs/docs/Takacs126.pdf (accessed on 10 December 2004).

23. Schubert, S.D.; Park, C.K.; Wu, C.Y. A multi-year assimilation with the GEOS-1 system: overview and results. In NASA Technical Report Series on Global Modeling and Data Assimilation; Suarea, M.J., Ed.; NASA: Washington, DC, USA, 1995.

24. Simmons, A.J.; Gibson, J.K. The ERA-40 Project Plan. ECMWF Re-Analysis Project Report Series No. 1. 2000. Available online: https://www.ecmwf.int/sites/default/files/elibrary/2000/12272-era-40-project-plan.pdf (accessed on 31 March 2000).

25. Kazutoshi, O.; Junichi, T.; Hiroshi, K.; Masami, S. The JRA-25 reanalysis. J. Meteorol. Soc. Jpn. 2007, 85, 369-432.

26. Simmons, A.; Uppala, S.; Dee, D.; Kobayashi, S. ERA-Interim: New ECMWF Reanalysis Products from 1989 Onwards. ECMWF Newsletter, No. 110; ECMWF: Reading, UK, 2007; Volume 110, pp. 25-35.

27. Ebita, A. The Japanese 55-year reanalysis "JRA-55": An interim report. Sola 2011, 7, 149-152. [CrossRef]

28. Compo, G.P.; Whitaker, J.S.; Sardeshmukh, P.D.; Matsui, N.; Allan, R.J.; Yin, X.; Gleason, B.E.; Vose, R.S.; Rutledge, G.; Bessemoulin, P.; et al. The twentieth century reanalysis project. Q. J. R. Meteorol. Soc. 2011, 137, 1-28. [CrossRef]

29. Smirnov, A.; Holben, B.N.; Slutsker, I.; Giles, D.M.; McClain, C.R.; Eck, T.F.; Sakerin, S.M.; Macke, A.; Croot, P.; Zibordi, G.; et al. Maritime aerosol network as a component of aerosol robotic network. J. Geophys. Res. 2009, 114. [CrossRef]

30. Olaf, S.; Johannes, F.; Antje, I.; Johannes, W.K.; Martin, G.S. Global reactive gases forecasts and reanalysis in the MACC project. J. Integr. Environ. Sci. 2012, 9, 57-70.

31. Zhao, T.B.; Xu, Z.B. Preliminary comparison and analysis between ERA-40, NCEP-2 reanalysis and observations over China. Clim. Environ. Res. 2006, 11, 14-32.

32. Huang, G. The assessment and difference of the interdecadal variations of climate change in northern part of China with the NCEP/NCAR and ERA-40 reanalysis data. Clim. Environ. Res. 2006, 11, 310-320.

33. Higgins, R.W.; Kousky, V.E.; Silva, V.B.; Becker, E.; Xie, P. Intercomparison of daily precipitation statistics over the United States in observations and in NCEP reanalysis products. J. Clim. 2010, 23, 4637-4650. [CrossRef]

34. Silva, V.B.; Kousky, V.E.; Higgins, R.W. Daily precipitation statistics for South America: An intercomparison between NCEP reanalyses and observations. J. Hydrometeorol. 2011, 12, 101-117. [CrossRef] 
35. Gerald, A.M.; Curt, C.; Thomas, D.; Mojib, L.; Bryant, M.; John, F.B.; Ronald, J.S.; Karl, E.T. The WCRP CMIP3 multimode dataset: A new era in climate change research. Bull. Am. Meteorol. Soc. 2007, 88, 1383-1394.

36. Wood, A.W.; Leung, L.R.; Sridhar, V.; Lettenmaier, D.P. Hydrologic implications of dynamical and statistical approaches to downscale climate model outputs. Clim. Chang. 2004, 62, 189-216. [CrossRef]

37. Lu, G.H.; Wu, Z.Y.; Lei, W.; Zhang, J.Y. Application of a coupled atmospheric-hydrological modeling system to real-time flood forecast. Adv. Water Sci. 2007, 16, 847-852.

38. Wang, C. The Impact Climate Change on Runoff in Qilian Mountain-A Case Study in Upper Reaches of Heihe River Basin. Ph.D. Thesis, Lanzhou University, Lanzhou, China, 2010.

39. Jeremy, P. Examples of simulations with the latest version of the RegCM. A little taste of the RegCM. Examples of simulations. Europe East Asia simulation of the monsoon west Africa simulation of the monsoon sensitivity to the convective closure assumption North America-PowerPoint PPT presentation. In Proceedings of the ITCP Workshop on the Theory and Use of Regional Climate Model, Trieste, Italy, 26 May-6 June 2003.

40. Fischer, G.; Nachtergaele, F.; Prieler, S.; van Velthuizen, H.T.; Verelst, L.; Wiberg, D. Global Agro-Ecological Zones Assessment for Agriculture (GAEZ 2008); IIASA: Laxenburg, Austria; FAO: Rome, Italy, 2008.

41. Zhang, Q.; Zhang, X. Impacts of predictor variables and species models on simulating Tamarix ramosissima distribution in Tarim Basin, northwestern China. J. Plant Ecol. 2012, 5, 337-345. [CrossRef]

42. Liu, S.Y.; Yao, X.J.; Guo, W.Q. The contemporary glaciers in China based on the Second Chinese Glacier Inventory. Acta Geogr. Sin. 2015, 70, 3-16.

43. Guo, W.Q.; Liu, S.Y.; Yao, X.J. The Second Glacier Inventory Dataset of China; Cold and Arid Regions Science Data Center at Lanzhou: Lanzhou, China, 2014.

44. Jafet, C.M.; Alexander, J.B.; Bernhard, W.; Hong, Y. Improved SWAT model performance with time-dynamic voronoi tessellation of climatic input data in Southern Africa. J. Am. Water Resour. Assoc. 2012, 48, 480-493.

45. Meng, X.Y.; Wang, H. Investigating spatiotemporal changes of the land-surface processes in Xinjiang using high-resolution CLM3.5 and CLDAS: Soil temperature. Sci. Rep. 2017, 7, 13286. [CrossRef] [PubMed]

46. Meng, X.Y.; Wang, H.; Chen, J. Profound impacts of the China meteorological assimilation dataset for SWAT model (CMADS). Water 2019, 11, 832. [CrossRef]

47. Meng, X.Y.; Wang, H.; Shi, C.; Wu, Y.; Ji, X. Establishment and evaluation of the China meteorological assimilation driving datasets for the SWAT model (CMADS). Water 2018, 10, 1555. [CrossRef]

48. Meng, X.Y.; Wang, H. Significance of the China meteorological assimilation driving datasets for the SWAT model (CMADS) of East Asia. Water 2017, 9, 765. [CrossRef]

49. Meng, X.Y.; Wang, H.; Lei, X.H.; Cai, S.Y.; Wu, H.J. Hydrological modeling in the Manas River Basin using soil and water assessment tool driven by CMADS. Teh. Vjesn. 2017, 24, 525-534.

50. Cao, Y.; Zhang, J.; Yang, M. Application of SWAT model with CMADS data to estimate hydrological elements and parameter uncertainty based on SUFI-2 algorithm in the Lijiang River Basin, China. Water 2018, 10, 742. [CrossRef]

51. Liu, J.; Shanguan, D.; Liu, S.; Ding, Y. Evaluation and hydrological simulation of CMADS and CFSR reanalysis datasets in the Qinghai-Tibet Plateau. Water 2018, 10, 513. [CrossRef]

52. Shao, G.; Guan, Y.; Zhang, D.; Yu, B.; Zhu, J. The impacts of climate variability and land use change on streamflow in the Hailiutu River Basin. Water 2018, 10, 814. [CrossRef]

53. Vu, T.T.; Li, L.; Jun, K.S. Evaluation of multi satellite precipitation products for streamflow simulations: A case study for the Han River Basin in the Korean Peninsula, East Asia. Water 2018, 10, 642. [CrossRef]

54. Zhao, F.; Wu, Y. Parameter uncertainty analysis of the SWAT model in a mountain-loess transitional watershed on the Chinese Loess Plateau. Water 2018, 10, 690. [CrossRef]

55. Zhou, S.; Wang, Y.; Chang, J.; Guo, A.; Li, Z. Investigating the dynamic influence of hydrological model parameters on runoff simulation using sequential uncertainty fitting-2-based multilevel-factorial-analysis method. Water 2018, 10, 1177. [CrossRef]

56. Gao, X.; Zhu, Q.; Yang, Z.; Wang, H. Evaluation and hydrological application of CMADS against TRMM 3B42V7, PERSIANN-CDR, NCEP-CFSR, and gauge-based datasets in Xiang River Basin of China. Water 2018, 10, 1225. [CrossRef]

57. Tian, Y.; Zhang, K.; Xu, Y.-P.; Gao, X.; Wang, J. Evaluation of potential evapo-transpiration based on CMADS reanalysis dataset over China. Water 2018, 10, 1126. [CrossRef] 
58. Qin, G.; Liu, J.; Wang, T.; Xu, S.; Su, G. An integrated methodology to analyze the total nitrogen accumulation in a drinking water reservoir based on the SWAT model driven by CMADS: A case study of the Biliuhe Reservoir in Northeast China. Water 2018, 10, 1535. [CrossRef]

59. Guo, B.; Zhang, J.; Xu, T.; Croke, B.; Jakeman, A.; Song, Y.; Yang, Q.; Lei, X.; Liao, W. Applicability assessment and uncertainty analysis of multi-precipitation datasets for the simulation of hydrologic models. Water 2018, 10, 1611. [CrossRef]

60. Dong, N.P.; Yang, M.X.; Meng, X.Y.; Liu, X. CMADS-driven simulation and analysis of reservoir impacts on the streamflow with a simple statistical approach. Water 2018, 11, 178. [CrossRef]

61. Guo, D.; Wang, H.; Zhang, X.; Liu, G. Evaluation and analysis of grid precipitation fusion products in Jinsha River Basin based on China meteorological assimilation datasets for the SWAT Model. Water 2019, 11, 253. [CrossRef]

62. Yuan, Z.; Xu, J.; Meng, X.; Wang, Y.; Yan, B. Impact of climate variability on blue and green water flows in the Erhai Lake Basin of Southwest China. Water 2019, 11, 424. [CrossRef]

63. Li, Y.; Wang, Y.; Zheng, J.; Yang, M. Investigating Spatial and Temporal Variation of Hydrological Processes in Western China Driven by CMADS. Water 2019, 11, 435. [CrossRef]

64. Zhao, X.; Xu, S.; Liu, T.; Qiu, P.; Qin, G. moisture distribution in sloping black soil farmland during the freeze-thaw period in northeastern China. Water 2019, 11, 536. [CrossRef]

65. Liu, X.; Yang, M.; Meng, X.; Wen, F.; Sun, G. Assessing the impact of reservoir parameters on runoff in the Yalong River Basin using the SWAT Model. Water 2019, 11, 643. [CrossRef]

66. Zhang, L.; Meng, X.; Wang, H.; Yang, M. Simulated runoff and sediment yield responses to land-use change using the SWAT model in northeast China. Water 2019, 11, 915. [CrossRef]

67. Abbaspour, K.C.; Vejdani, M.; Haghighat, S. 2007b SWAT-CUP calibration and uncertainty programs for SWAT. In MODSIM $2007 b$ International Congress on Modelling and Simulation; Oxley, L., Kulasiri, D., Eds.; Modelling and Simulation Society of Australia and New Zealand Christchurch: Australiasia, New Zealand, 2007; pp. 1596-1602.

68. Abbaspour, K.C.; Johnson, C.A. Estimating uncertain flow and transport parameters using a sequential uncertainty fitting procedure. Vadouse Zone J. 2004, 3, 1340-1352. [CrossRef]

69. Abbaspour, K.C.; Yang, J.; Maximov, I.; Siber, R.; Bogner, K.; Mieleitner, J.; Zobris, J.T.; Srinivasan, R. Modelling hydrology and water quality in the pre-alpine/alpine Thur watershed using SWAT. J. Hydrol. 2007, 333, 413-430. [CrossRef]

70. Abbaspour, K.C. Swat-Cup2: SWAT Calibration and Uncertainty Programs Manual Version 2, Department of Systems Analysis; Integrated Assessment and Modelling (SIAM), Eawag, Swiss Federal Institute of Aquatic Science and Technology: Duebendorf, Switzerland, 2011; p. 106.

71. Wu, Y.; Liu, S.; Huang, Z.; Yan, W. Parameter optimization, sensitivity and uncertainty analysis of an ecosystem model at a forest flux tower site in the United States. J. Adv. Model. Earth Syst. 2014, 6, 405-419. [CrossRef]

72. Wu, Y.; Liu, S. Improvement of the R-SWAT-FME framework to support multiple variables and multi-objective functions. Sci. Total Environ. 2014, 466, 455-466. [CrossRef]

73. Tu, M.C.; Smith, P. Modeling pollutant buildup and washoff parameters for SWMM based on land use in a semiarid urban watershed. Water Air Soil Pollut. 2018, 229, 121. [CrossRef]

74. Abbaspour, K.C.; Rouholahnejad, E.R.; Vaghefi, S.; Srinivasan, R.; Yang, H.; Kløve, B. A continental-scale hydrology and water quality model for Europe: Calibration and uncertainty of a high-resolution large-scale SWAT model. J. Hydrol. 2015, 524, 733-752. [CrossRef]

75. Nash, J.E.; Sutcliffe, J.V. River flow forecasting through conceptual models: Part 1-A discussion of principles. J. Hydrol. 1970, 10, 282-290. [CrossRef]

76. Schaefli, B.; Gupta, H.V. Do Nash values have value? Hydrol. Process. 2007, 21, 2075-2080. [CrossRef]

77. Santhi, C.; Arnold, J.G.; Williams, J.R.; Dugas, W.A. Application of a watershed model to evaluate management efforts on point and nonpoint source pollution. Trans. ASAE. 2001, 44, 1559-1570. [CrossRef]

78. Ahmad, H.M.; Sinclair, A.; Jamieson, R.; Madani, A.; Hebb, D.; Havard, P.; Yiridoe, E.K. Modeling sediment and nitrogen export from a rural watershed in Eastern Canada using the soil and water assessment tool. J. Environ. Qual. 2011, 40, 1182-1194. [CrossRef] [PubMed] 
79. Moriasi, D.N.; Arnold, J.G.; van Liew, M.W.; Bingner, R.L.; Harmel, R.D.; Veith, T.L. Model evaluation guidelines for systematic quantification of accuracy in watershed simulations. Trans. ASAE. 2012, 50, 885-900. [CrossRef]

80. Yin, Z.L.; Xiao, H.L.; Zou, S.B.; Zhu, R.; Lu, Z.X.; Lan, Y.C.; Shen, Y.P. Progress of the research on hydrological simulation in the mainstream of the Heihe River, Qilian Mountains. J. Glaciol. Geocryol. 2013, 35, 438-446. 